\title{
AN EXPERIMENTAL STUDY ON THE CORROSION SUSCEPTIBILITY OF RECYCLED STEEL FIBER REINFORCED CONCRETE
}

\author{
Cristina Frazão', Belén Díaz², Joaquim Barros³, \\ Alexandre Bogas ${ }^{4}$ and Fatih Toptan ${ }^{5}$
}

\begin{abstract}
Steel fibers resulting from the industry of tire recycling can be efficiently employed in concrete to improve its mechanical performance, such as post-cracking load bearing and energy absorption capacity. Under chloride attack, an important aspect of Recycled Steel Fiber Reinforced Concrete (RSFRC) durability is its corrosion resistance. However, the insufficient knowledge on this domain contributes for a conservative design philosophy, which can compromise the cost competitiveness of RSFRC and prevent its application in elements where this occurrence, even eventual, is not acceptable.

In the present work, an experimental program was performed with the aim of assessing the corrosion susceptibility of RSFRC including the characterization of the micro-mechanical properties and the corrosion resistance of recycled steel fiber (RSF) by means of nano-indentation testing, electrochemical monitoring techniques and scanning electron microscopy (SEM) analysis. The influence of the small rubber debris attached to the RSF surface was also analyzed by using two distinct pre-treatment methods. The adhesive bond behavior between the RSF and the surrounding self-compacting concrete (SCC) matrix was analyzed by performing monotonic RSF pullout tests. Double edge wedge splitting (DEWS) tests were conducted for evaluating the corrosion effects on the post-cracking response of RSFRC.
\end{abstract}

Keywords: Corrosion, RSF, fiber pullout test, RSFRC, splitting tensile test.

\footnotetext{
${ }^{1} \mathrm{PhD}$ Student, ISISE, Dept. of Civil Engineering, University of Minho, Campus de Azurém, Guimarães, Portugal, e-mail: frazao_cristina@hotmail.com, webpage: http://www.isise.net.

${ }^{2}$ Assistant Professor, ENCOMAT, Dept. of Materials Engineering, Applied Mechanics and Construction, University of Vigo, Spain, e-mail: belenchi@uvigo.es, webpage: http://www.encomat.uvigo.es.

${ }^{3}$ Full Professor, ISISE, Dept. of Civil Engineering, University of Minho, Campus de Azurém, Guimarães, Portugal, e-mail: barros@civil.uminho.pt, webpage: http://www.isise.net.

${ }^{4}$ Assistant Professor, ICIST, Dept. of Civil Engineering and Architecture, Technical University of Lisbon, Portugal, e-mail: abogas@civil.ist.utl.pt, webpage: http://www.ceris.pt.

5Assistant Professor, CMEMS, Dept. of Mechanical Engineering, University of Minho, Campus de Azurém, Guimarães, Portugal, e-mail: ftoptan@dem.uminho.pt, webpage: http://www.mems.dei.uminho.pt.
} 


\section{INTRODUCTION}

The environmental damage caused by the indiscriminate disposal of large amounts of waste tires into landfills increased over the past years creating a serious problem to be solved [1, 2]. Following the implementation of various European Union directives, the use of material recovered from waste tires has become the most sustainable strategy for turning viable the investments on the recycling waste tires [1-3]. With this aim, mechanical and thermal degradation processes, such as tire shredding, pyrolysis and cryogenic reduction, are currently utilized by the tire recycling industry $[2,3]$.

Recycled Steel Fibers (RSF), derived from the tire recycling industry, can be an effective concrete reinforcement for structural and non-structural applications, with great economic and ecological beneficial impact [1-4]. The available bibliography on the subject shows that RSF reinforcement can decrease significantly the brittle behavior of cement based materials by improving their toughness and post-cracking resistance [5-10]. RSF are also used in concrete to restrain the crack opening by bridging the crack surfaces, which leads to an increase in terms of post-cracking load bearing and energy absorption capacity with beneficial consequences in terms of concrete durability [10-13]. However, the crack restraint effectiveness depends on the bond behavior of the fiber/matrix interface [14].

In an environment containing chlorides, an important aspect of Fiber Reinforced Concrete (FRC) durability is the corrosion resistance [15-18]. Corrosive agents, liquid or gaseous, may penetrate the concrete through one of the three main transport mechanisms: diffusion; capillary transport; permeation. These transport mechanisms are highly dependent on the concrete cracking state. An increase of the crack width, not only leads to a more permeable concrete, but also enhances the possibility of fiber corrosion. However, the concrete permeability decreases significantly by increasing the fiber content, due to the reduction of shrinkage cracks [19]. In fact, by limiting the crack width of FRC to $0.3 \mathrm{~mm}$, it seems that the corrosion is limited to the fibers located at the surface, which has only an aesthetic detrimental impact [18, 20-21].

Due to their large surface area to volume ratio, steel fibers are more effectively protected by the lime rich layer than the large diameter bars used in conventional reinforced concrete [22]. In fact, steel fibers are protected by the high alkalinity $(\mathrm{pH}>13.5)$ of the pore solution of concrete that causes the formation of a protective oxide film on the steel fibers surface, passivating them [22].

This film can be destroyed when the chloride ions penetrate into the FRC and exceed the critical threshold 
chloride content [22]. However, even in a corrosive environment, such as deicing salt and sea water containing chloride ions with relatively high concentration, it has been reported that only steel fibers near the concrete surface are susceptible to corrosion [18].

The insufficient knowledge on the deterioration mechanisms involving fiber corrosion contributes for a conservative design philosophy, which limits the mobilization of the full potential of Steel Fiber Reinforced Concrete (SFRC) [23]. In fact, some design guidelines recommend do not take into account the contribution of a certain layer depth of fiber reinforcement in the flexural resistance of SFRC members [24].

Several researchers have investigated the effect of corrosion on SFRC [17-18, 20-22, 25-39]. All authors agree on the point that the steel fiber corrosion is much less severe in SFRC than in steel rebar reinforced concrete structures. However, the conclusions presented in these works are not sufficient to attest the corrosion effects on the durability of Recycled Steel Fiber Reinforced Concrete (RSFRC). To the best of authors' knowledge, no research study was carried out concerning the behavior of RSF in concrete under the influence of corrosion. In this way, the main purpose of this experimental study was to investigate the corrosion susceptibility of recycled steel fibers and evaluate its effect on the post-cracking behavior of RSFRC exposed to corrosive environment.

Electrochemical techniques can be used to assess, control and investigate the corrosion of RSF caused by corrosive attack of chloride ions. In this work, electrochemical tests and scanning electron microscopy (SEM) analysis were carried out to analyze the corrosion susceptibility of RSF. Results were compared with those obtained with industrial steel fibers (ISF) taking into account identical experimental conditions [21].

To study the corrosion influence on the post-cracking response of RSFRC, Double Edge Wedge Splitting (DEWS) tests were conducted according with a new test method [40] that arose from the combination of the methodology proposed by di Prisco et al. [41] for indirect evaluation of the mode I fracture properties of FRC and the Modified Splitting Tensile Test (MSTT) introduced by a group of researchers from the University of Minho [42-43]. The methodology adopted and the experimental results are presented and discussed.

In addition, RSF have irregular geometric properties and, when obtained from the shredding process often contain small rubber particles attached to their surface [2]. Therefore, in order to assess the influence of this attached rubber in the performance of RSF as concrete reinforcement and in its corrosion resistance, two distinct methods were used to eliminate the small percentage of rubber attached to the fiber surface: manual 
polishing of the fiber surface with sandpaper; pre-treatment of the fibers at high temperatures. In order to assess the influence of these pre-treatment methods in the micro-mechanical properties of RSF, nanoindentation technique was employed to measure the mechanical properties of RSF, and monotonic fiber pullout tests were performed to assess the adhesive bond between the RSF and the matrix of a Self-Compacting Concrete (SCC).

\section{EXPERIMENTAL PROGRAM}

\subsection{Micro-mechanical properties of RSF}

The recycled steel fibers used in this research were recovered by a shredding process of post-consumed truck tires. The steel was separated from the rubber by an electromagnetic separator, but the majority of RSF still contained some attached rubber in their surface. These RSF have irregular geometry with various lengths and diameters (Figure 1). According to the data given by the supplier, on average, the RSF are characterized by $20 \mathrm{~mm}$ in length $\left(I_{f}\right), 0.15 \mathrm{~mm}$ in diameter $\left(d_{f}\right)$, an aspect ratio $\left(I_{f} / d_{f}\right)$ of 166 , and a tensile strength as high as $2850 \mathrm{MPa}$.

\subsubsection{Pre-treatment of RSF to remove rubber debris attached to fiber surface}

In order to remove great part of the rubber attached to the RSF surface, two different methods were considered: manual polishing of the fiber surface with \#180 SiC (Silicon Carbide Grinding) Paper (time consuming method, industrially impracticable); pre-treatment of fibers at high temperatures, burning the attached rubber of lower melting point.

The range of decomposition temperatures of the rubber waste was settled from thermogravimetric analysis (TGA). Using this technique, the mass loss of RSF versus temperature was monitored up to $700^{\circ} \mathrm{C}$ at a constant heating rate of $10^{\circ} \mathrm{C} / \mathrm{min}$. It was found that heating at $10^{\circ} \mathrm{C} / \mathrm{min}$ up to $350^{\circ} \mathrm{C}$ followed by 60 minutes at this temperature was adequate to eliminate the rubber debris from the RSF surface, as will be discussed in section 3.1 .

In sum, the following three classes of RSF were considered in the experimental program: Class 1-Reference 
RSF, without pretreatment, as were received; Class 2 - RSF pre-treated at 350두 Class 3 - Polished RSF. Polishing of RSF led to the most uniform fiber surface, as shown in the SEM micrographs of Figures 1c and 4 .

\subsubsection{Nano-indentation testing}

The Young's modulus and hardness of RSF and ISF were determined by means of nano-indentation tests. The hooked-ends ISF with $60 \mathrm{~mm}$ length $\left(l_{f}\right), 0.90 \mathrm{~mm}$ diameter $\left(d_{f}\right)$, an aspect ratio $\left(I_{f} / d_{f}\right)$ of 67 , a mass of about $5.1 \mathrm{mg} / \mathrm{mm}$ and a tensile yield stress of $1100 \mathrm{MPa}$, were the same used by Frazão et al. [21] to study their corrosion susceptibility. For comparison purposes, the following two types of ISF were considered: Class 1 - Reference ISF: without pretreatment, as were received; Class 2 - ISF pre-treated at $350^{\circ} \mathrm{C}$.

A standard Berkovich nanoindenter was forced into a particular site of the sample by applying an increasing load. A new continuous stiffness measurement (CSM) technique on a MTS nano-indenter XP was employed for this analysis. In this technique the mechanical properties are obtained by applying a small oscillating force to the indenter and measuring the amplitude and phase shift of the oscillations that result. The indenter was forced to penetrate into the surface to a depth of $1000 \mathrm{~nm}$, low enough to avoid any interference. The Young modulus and hardness of steel fibers were then estimated based on this dynamic indentation procedure. This technique is the most appropriate for this type of fibers since its accuracy is higher than that of common methodologies.

\subsubsection{Pullout tests}

\subsubsection{Materials and mix composition}

One SCC mixture was produced with CEM I 42.5R Portland cement (C), limestone filler (LF), fine river sand (FS) (maximum aggregate size of $1.19 \mathrm{~mm}$ and fineness modulus of 1.91), coarse river sand (CS) (maximum aggregate size of $4.76 \mathrm{~mm}$ and fineness modulus of 3.84) and crushed granite (CA) (maximum aggregate size of $19.10 \mathrm{~mm}$ and fineness modulus of 6.64$)$, water (W), a polycarboxylate based superplasticizer (SP) with the commercial designation ViscoCrete 3005 and a viscosity modifying admixture (VMA). The physical characteristics of the cement and limestone filler used can be found in Frazão et al. [21]. 
Table 1 includes the SCC composition. The mix design was based on the packing density optimization method suggested in Barros et al. [44]. The mixing procedure and other fresh properties of SCC can be found elsewhere [44]. The main fresh properties of SCC, namely the slump-flow and V-funnel time were determined according to EFNARC [45]. An average slump-flow of $521 \mathrm{~mm}$ and a flow time of $5.5 \mathrm{~s}$ was achieved without significant segregation.

The compressive strength and the elastic modulus of the SCC were determined at 28 days in cylinders of 150 $\mathrm{mm}$ diameter and $300 \mathrm{~mm}$ height according to the EN 12390-3 [46] and LNEC E397 [47], respectively. Details about the test procedures can be found elsewhere [20]. The average values of compressive strength $\left(f_{c m}\right)$ and Young's modulus $\left(E_{c m}\right)$ were $31.5 \mathrm{MPa}$ and $23.7 \mathrm{GPa}$, respectively. The coefficient of variation was lower than $2 \%$ in both tests.

For the pullout tests a single RSF was centrally embedded on a cylindrical SCC specimen with $88 \mathrm{~mm}$ diameter and $80 \mathrm{~mm}$ height. The RSF was positioned as perpendicular as possible, with an embedded length of $20 \mathrm{~mm}$ (Figure 2a). Prior to testing, two aluminum plates were attached to the free loaded end of the RSF (Figure 2b), in order to avoid undesired rupture or slippage of the fiber at the gripping system of the testing machine.

\subsubsection{Pullout test setup}

The pullout test setup was defined according to Abrishambaf et al. [48]. Monotonic single fiber pullout tests were performed until a sufficiently high level of slip (>6 mm) occurred in the pullout load-slip response $(P-\Delta L)$. Since the maximum pullout loads were relatively low, a high precision load cell of $10 \mathrm{kN}$ capacity was adopted. This load cell was installed between the servo-actuator and the grip (Figure 3b). The single pullout specimen was accommodated in a steel frame to fix it [49], which was designed to prevent the confinement of the fiber due to friction forces developed in the steel reaction plate. The test control procedure guaranteed a stable response during the debonding process of the fiber.

To measure the fiber's slip during the pullout procedure, three Linear Variable Differential Transformers (LVDTs with linear stroke $+/-5 \mathrm{~mm}$ ) were installed on the back side of the grip, by means of aluminum cubic supports (Figure $3 \mathrm{c}, \mathrm{d}$ ). The fiber slip at the grip during the pullout process was also measured using a VMS-004D-400x USB Microscope with a 2 Mega Pixels camera [48]. Finally, the test was controlled by an LVDT installed on the actuator, and adopting a displacement rate of $3 \mu \mathrm{m} / \mathrm{s}$ up to the slip of $3 \mathrm{~mm}$, followed by $4 \mu \mathrm{m} / \mathrm{s}$ until the end of the test $(15 \mathrm{~mm})$. 


\subsection{Characterization of RSF corrosion using electrochemical monitoring techniques}

The RSF used for electrochemical tests were selected with similar geometric properties in order to reduce the dispersion of results. The length of the selected RSF varied between $49-63 \mathrm{~mm}$, for an average diameter of $0.34 \mathrm{~mm}$ and an average mass of $0.86 \mathrm{mg} / \mathrm{mm}$.

The corrosion resistance of RSF was measured in accordance to the electrochemical method adopted by [21] to assess the corrosion resistance of ISF. The following methodologies were considered: open circuit potential, OCP, ( $\left.E_{O C P}\right)$; potentiodynamic polarization; linear polarization.

To perform these electrochemical tests, an electrochemical cell was prepared on a particular RSF/solution system. This cell consisted on the RSF to be investigated (working electrode), $3.5 \%$ wt. $\mathrm{NaCl}$ solution in which the tests were performed, the implements required to conduct the measurement (the counter electrode (platinum), the reference electrode (SCE - Saturated Calomel Electrode)), and the potentiostat/galvanostat controlled by the software VoltaMaster-4 [50] for monitoring electrochemical tests.

Prior to performing the tests, the fibers were washed with distilled water and ultrasonically cleaned in propanol for $15 \mathrm{~min}$ in order to decontaminate the surface of the fibers. The RSF were weighed before and after the electrochemical tests in order to quantify the loss of fiber mass by corrosion. About half length of the fiber surface that was not in contact with the chloride solution was sealed with Lacomit varnish in order to avoid its corrosion. The remaining length was immersed in the $3.5 \% \mathrm{wt}$. $\mathrm{NaCl}$ solution.

Table 2 summarizes the tests carried out considering the three defined classes of RSF. The tests were divided in ten series that also take into account different periods of chloride immersion, as well as distinct electrochemical procedures. In each series, at least three RSF of the same type were tested under the same conditions

For series I, reference class 1 RSF was immersed in chloride solution and the $E_{O C P}$ was recorded during 60 min before the cyclic potentiodynamic polarization was implemented. The cyclic polarization tests consisted on a continuous sweep upward and downward potential at a constant rate of $0.6 \mathrm{mV} / \mathrm{s}$, from the cathodic potential $-300 \mathrm{mV}$ below the value of $E_{O C P}$ up to the anodic potential $+250 \mathrm{mV}$ and returning to the initial cathodic potential. This cyclic polarization was initially performed in order to identify the type of corrosion attack, i.e., uniform (general) or non-uniform (localized) attack. 
In Series II and III, potentiodynamic polarization tests were performed on polished RSF of class 3 , respectively, after 60 minutes and 7 days of immersion. In these potentiodynamic polarization tests, a continuous sweep and upward potential was executed from $-300 \mathrm{mV}$ below the value of $E_{O C P}$ up to 1000 $\mathrm{mV}$, at a constant rate of $0.6 \mathrm{mV} / \mathrm{s}$. Prior to the polarization tests, the $E_{O C P}$ was recorded during the 60 minutes of immersion in series II and for 30 minutes in the beginning and after 24 h, 48 h, 3 days, 4 days and 7 days of immersion in series III.

The series IV had the purposes of evaluating the weight loss of polished RSF after 7 days of immersion in $3.5 \%$ wt. $\mathrm{NaCl}$ solution. In this case, RSF were weighed before and after the immersion period.

In series V, VII and IX tests, each RSF class was tested for linear polarization after 30 minutes of immersion in $3.5 \%$ wt. $\mathrm{NaCl}$ solution, in which $E_{O C P}$ was recorded. In the linear polarization tests, a continuous sweep upward and downward potential of an amplitude of $\pm 30 \mathrm{mV}$ was executed in turn of the value of $E_{O C P}$, at a constant rate of $0.1 \mathrm{mV} / \mathrm{s}$. The same test was performed in series VI, VIII and X, but after 7 days of immersion.

\subsection{Post-cracking behavior of RSFRC under corrosion action obtained from splitting tests}

\subsubsection{Mix composition and specimen production}

One concrete mixture of RSFRC was produced using the same materials presented in section 2.1.3.1 and a RSF content of $60 \mathrm{~kg} / \mathrm{m}^{3}$. The RSF composition indicated in Table 1 was defined taking into account the work of Zamanzadeh et al. [5], involving an experimental aggregate packing method for fiber reinforced concrete. The workability of fresh concrete was determined by the Abrams slump-flow test according to the recommendation of EN 12350-8 [51]. The average slump-flow was $510 \mathrm{~mm}$, which is within the consistency of class F4 (fluid concrete), according to the EN 206-1 [52].

For each class of RSF, two $\phi 150 \times 300 \mathrm{~mm}$ cylindrical specimens were casted. The filled molds were kept for 3 days in the laboratory environment (average temperature of $21^{\circ} \mathrm{C}$ and relative humidity of $60 \%$ ), with the exposed face protected with a plastic film, after which they were demolded and stored in the laboratory environment until 28 days of age.

Four specimens of $\phi 150 \times 60 \mathrm{~mm}$ were obtained from each cylindrical specimen, as shown in Figure 5. In each 
specimen, $5 \mathrm{~mm}$ deep notches were executed parallel to the loading direction, in order to set the specimen's fracture surface along the notched plane (notch 2 in Figure 5). Following the procedure adopted by di Prisco et al. [41], a V-shaped groove with $45^{\circ}$ inclination was also implemented at the extremities of the notched plane, as illustrated in Figure 5 (notch 1). The objective of this V-shaped groove was to induce a stress field corresponding to an almost pure mode I fracture in the notched plane.

After 28 days of curing, 4 specimens of each RSF class were immersed during 10 days in $3.5 \%$ wt. $\mathrm{NaCl}$ solution in order to induce fiber corrosion. The remaining specimens were cured in water, without corrosion induction, for comparison purposes. The chloride immersion was carried out before specimens were notched.

\subsubsection{Experimental Setup}

The splitting tests were conducted under displacement control using an external LVDT that was positioned on the actuator to control the vertical deformation of the specimen. The following displacement rates were adopted: $1.0 \mu \mathrm{m} / \mathrm{s}$ up to the displacement of $2.0 \mathrm{~mm} ; 2.0 \mu \mathrm{m} / \mathrm{s}$ from $2.0 \mathrm{~mm}$ up to $3.0 \mathrm{~mm} ; 4.0 \mu \mathrm{m} / \mathrm{s}$ until the end of the test. For an accurate detection and tracking of the crack propagation, five LVDTs were used to measure the crack opening displacement along the fracture surface (Figure 6) - three on the front face and two on the rear face of the specimen. The load was registered by means of a $150 \mathrm{kN}$ load cell. All the splitting tensile tests were carried out 75 days after casting. The test setup was defined based on the combination of DEWST and MSTT, which tried to overcome the limitations of each test method, deviating the crosswise compressive stresses from the fractured section while a unique fracture plane is likely to be obtained [40].

After the splitting tensile tests, each face of the fracture surface was divided in four equal regions in order to evaluate the fiber distribution. The fiber distribution was evaluated by counting the number of effective fibers crossing the fractured surfaces. A fiber was considered effective when it was broken or when its length was visible (pullout failure) [40].

\section{RESULTS AND DISCUSSION}

\subsection{Thermogravimetric analysis (TGA)}

Figure 7 shows the TGA curve of RSF. The major mass loss occurred between $300^{\circ} \mathrm{C}$ and $450^{\circ} \mathrm{C}$. Considering this preliminary results, RSF were subjected to the following temperatures during 1 hour: 
$300^{\circ} \mathrm{C}, 350^{\circ} \mathrm{C}, 400^{\circ} \mathrm{C}$ and $450^{\circ} \mathrm{C}$. Figure 8 shows the photos taken with a digital microscope after each of these heat treatments. From visual inspection and weight variation analysis, it was found that temperatures above $350^{\circ} \mathrm{C}$ were effective to remove the rubber waste from fibers surface. The temperature of $300^{\circ} \mathrm{C}$ was not effective since part of the rubber still remained on RSF surface (Figure 8). For this reason and also considering the economic point of view, the temperature of $350^{\circ} \mathrm{C}$ was defined for the heat pre-treatment of RSF (class 2).

\subsection{Nano-indentation results}

A recent study of Baldenebro et al. [53] has shown that the Young's modulus and hardness measured by nano-indentation are influenced by the precise size of the material samples, in particular when comparing fibers and larger specimens. They have measured lower values of these properties in the fibers than in samples of bulk materials. Therefore, as most of published works include data obtained from bulk samples, the comparison with the results obtained in this study must be cautious [53].

Various RSF and ISF have been multiple indented to guarantee an appropriate reproducibility and reliability. Figures 9 and 10 show the load-displacement curves obtained for tested fibers. In case of RSF of class 1 (reference), three different load ranges can be discernible, the HIGH range (100-160 mN), the MEDIUM range $(50-100 \mathrm{mN})$ and the LOW range $(0-50 \mathrm{mN})$, with $75.7 \%, 10.8 \%$ and $13.5 \%$ of the total number of indentations in each range, respectively. For RSF of class 2 (pre-heated at $350^{\circ} \mathrm{C}$ ), no indentations were recorded within the LOW load range, indicating to have occurred a homogenization of the steel structure due to temperature influence. In fact, $92.7 \%$ of the indentations are within the HIGH load range. The load-displacement curves corresponding to RSF of class 3 (polished) and ISF, lie in the same range, suggesting the existence of a more homogeneous matrix in comparison to the RSF of class 1 and 2. A summary of the average values of Young's Modulus and hardness is presented in Table 3. The RSF have a carbon content around $0.70 \%$, according to its chemical composition determined by X-ray Fluorescence (XRF) analysis. Although the precise microstructure of the RSF could not be yet identified, the high hardness measured $(6.4-10.3 \mathrm{GPa})$ agree to the existence of tempered martensite according to the literature [54]. A fully pearlitic structure can be excluded since the hardness value of such a material is below $3.5 \mathrm{GPa}[55]$. 
The lower hardness of ISF than that of RSF was expected due to the lower carbon amount of ISF (lower than $0.20 \%$, according to the supplier). The carbon content is a well-known factor that influences the hardness of the martensite. The obtained hardness values of ISF agrees to the existence of a martensitic structure [56].

Different trends were found when RSF and ISF were pre-treated at $350^{\circ} \mathrm{C}$. In fact, while the hardness increased in RSF, the opposite occurred in ISF. For the RSF, with a high carbon content, a significant amount of retained austenite is expected in the supplied quenched state [56]. Actually, for an AISI 1070 steel, the percentage of retained austenite can be calculated about $10 \%$ [55]. A possible reason for the increase of hardness in RSF in class 2 can be related to the transformation of that retained austenite during the heat treatment used to remove the superficial rubber. The treatment at $350^{\circ} \mathrm{C}$ eventually assisted the transformation of this retained austenite of the RSF (austenite that does not transform to martensite upon quenching), at least partially, into lower bainite, whose refinement of the microstructure leads to an increase in the properties [57]. This increment of hardness may have a negative effect on ductility since it becomes a more brittle material.

On the other hand, the heat treatment reduced the hardness of ISF. For such a low carbon steel, no retained austenite is expected [56], and then, the obtained hardness changes suggest a tempering of the existing martensite, which led to a softer tempered martensite [58]. In comparison to RSF of class 1 and 2 (Fig. 9a and 9b), the ISF had a more homogeneous microstructure, with a single distinguished phase (Fig. 10a and 10b). Accordingly, a greater variability could be calculated among the data obtained for the RSF of class 1 and 2 in comparison to the RSF of class 3 and ISF, as compiled in Table 3.

According to Fig. 9c and Table 3, the treatment by manual polishing (RSF of class 3 ) caused a homogenization of the RSF microstructure and increased the hardness of RSF. This increase in hardness can be explained by the transformation of the retained austenite into martensite due to the strain induced by plastic deformation that occurs during the polishing process (referenced in the literature by "straininduced martensitic transformation" [59]).

Concerning the Young's Modulus values, they are in the same range as those reported in the literature [60], except for RSF of class 1. As also reported in [61], the Young's Modulus did not significantly vary with temperature. The unexpected low value for the untreated RSF (132 GPa) can be just a consequence of the great variability observed in the indentations performed to this material (Fig. 9a). The large number 
of indentations in the low load range recorded for the as-received RSF, in comparison to the other fibers, have an influence in the obtained average Young's Modulus value. A great variability was also observed in the Young's Modulus values obtained for RSF of class 2 since the high temperatures were not fully effective in homogenizing the steel structure of all the fibers. The data discussed in this section allow to conclude that the RSF of class 1 and 2 are particularly heterogeneous from a microstructural point of view.

\subsection{Monotonic Pullout tests}

Figure 11 indicates the average pullout load versus end slip curves for the three tested classes of RSF. The slip was determined by averaging the readouts recorded in the three LVDTs installed on the grip (Figure 3).

Taking only into account the average pullout loads, we may conclude that the rubber debris attached to the RSF surface (class 1 ) had a minor effect in the pullout behavior of RSF, since the average pullout load was similar to those of clean RSF (classes 2 and 3) (Figure 11). However, this should be valid only when the rubber debris attached in the fiber surface does not cover a significant surface area. In fact, taking into account the pullout load versus slip curves of five types of RSF with very different rubber contents, it was found that for relevant amounts of rubber debris there was a significant decrease of the pullout strength with the increase of rubber (F1 and F2 - Fig. 12). For low amounts of rubber, which was more common, slight variations on rubber content was not significant (F3 and F4 - Fig. 12). In addition, the irregular shape of RSF had also a significant influence in the fiber pullout behavior, comparing F4 with F5 which practically are free of rubber (Fig. 12). As expected, the RSF with more irregular and twisted embedded length showed higher fiber pullout load and greater probability of fiber rupture (F4 and F5 Fig. 12). In sum, as shown in Figures 13a and 13c, a high dispersion of the results was obtained in these pullout tests (class 1 and 3), being essentially affected by two main factors; the amount of attached rubber and the fiber geometry.

Except for class 2 RSF, the failure mode of fibers always occurred by pullout. For the pre-treated RSF at $350^{\circ} \mathrm{C}$ (class 2 ) it was found that about $60 \%$ of the fibers had broken during the pullout tests (these results are not included in Figure 13b). For this reason, a low dispersion of the results was obtained in the tests of class 2 since a less number of pullout tests was considered ( 5 tests in class 2 comparing with 14 tests 
in class 1 and 11 tests in class 3). One the one hand, higher pullout loads were attained with the elimination of the rubber debris. On the other hand, this can be also attributed to the effect of higher temperatures on the fiber surface, which has increased the hardness and brittleness found in nanoindentation tests, as well as the formation of micro cracks, as shown in Figure $4 b$.

\subsection{Characterization of fiber corrosion by electrochemical tests}

The average values of Eocp during the immersion period of series I and III are presented in Figure 14. The values of RSF are compared with those of ISF reported in [21]. It was found that for 60 minutes of chloride immersion, the corrosion potential was approximately constant, both in RSF and ISF. In Series III, the corrosion potential sharply decreased after one day of immersion, indicating an increase in the general corrosion of the fiber. Afterwards, the potential of RSF fully stabilized up to 7 days of immersion as found in ISF. More positive corrosion potential values have been recorded for the RSF in comparison to the ISF. Electrochemically, this difference is very small (about $70 \mathrm{mV}$ ), and can be considered as insignificant.

According to the ASTM C876 [62], if $E_{O C P}$ is lower than $-276 \mathrm{mV}$, the probability of corrosion of reinforcing steel in concrete is greater than $90 \%$ when immersed in a $3.5 \%$ wt. $\mathrm{NaCl}$ solution. Assuming that this is also valid for steel fibers [21], a high probability of corrosion can be concluded for ISF and RSF.

Figure 15 shows the polarization curves obtained in the cyclic polarization tests performed on three RSF of class 1 after $1 \mathrm{~h}$ of chloride immersion (Series I). Small differences were found between different fibers. The obtained curves show that the corrosion of the reference RSF is generalized in its surface, since the current density values recorded in the reverse scan are smaller than those obtained in the forward scan, which means that there is no evidence of localized corrosion.

Figure 16 shows the polarization curves obtained for fiber 1 in test series II and III comparing with the homologous curves obtained with ISF [21]. Due to the reduced diameter of RSF comparing with that of ISF, the rupture of RSF occurred during the polarization (Figure $16 \mathrm{a} ; E=391.1 \mathrm{mV}$ ). To avoid this phenomenon in Series III, the upward potential was limited to up $100 \mathrm{mV}$.

Table 4 summarizes the values of corrosion potential, $E_{(i=0)}$, corrosion current density, $i_{\text {corr }}$, and 
polarization resistance, $R_{p}$, obtained from the potentiodynamic polarization curves of Series II and III. In both Series II and III, the $E_{(i=0)}$ of RSF presented more positive values compared to ISF, as also shown in Figure 16. This seems that the chemical composition of RSF surface (Cu species $-5.41 \%$ and $\mathrm{Zn}$ species $-3.53 \%$ of concentration determined by XRF) improved the corrosion performance of the steel [63,64].

However, the cathodic branches of polarization curves (oxygen and hydrogen reduction) achieved greater current values for RSF than ISF according to Figure 16, which means higher corrosion rates for RSF. It seems that RSF are more susceptible to corrosion than ISF because they showed higher values of $i_{\text {corr }}$ and lower values of $R_{p}$.

Regardless of the type of fiber (RSF or ISF), the coefficients of variation of the potentiodynamic polarization results were very high in some cases, being difficult to point a clear difference for all cases (Table 4). Therefore, it was decided to further perform linear polarization tests, which presented lower variability [65]. In fact, this test may provide more precise results, since they are carried out within a smaller range of potential sweep and at a lower scan speed in order to obtain the current response as linear as possible. These experiments are significantly less destructive and provide a more realistic assessment of the corrosion rate [65].

Table 5 shows the values of $E_{(i=0)}, i_{c o r r}$ and $R_{p}$ obtained in linear polarization tests from Series $V$ to $X$. As found for ISF [21], the values of $i_{\text {corr }}$ were greater than $0.2 \mu \mathrm{A} / \mathrm{cm}^{2}$ and hence, according to the literature $[66,67]$, all RSF classes evidenced high risk of corrosion. In addition, the high risk of corrosion is confirmed by the fairly low values of $R_{p}$. From the linear polarization technique it was also found that the obtained values of $i_{\text {corr }}$ did not vary significantly with the immersion time. Smaller values of standard deviations were obtained in the linear polarization tests when compared to potentiodynamic polarization tests.

As found in potentiodynamic tests, RSF exhibited higher $i_{\text {corr }}$ and lower $R_{p}$, showing higher corrosion rate than ISF. Taking into account the values of corrosion rate determined by the Faraday's Law, it was found that the level of corrosion in RSF were as high as 3.3 to 5.9 milli-inches $(0.08-0.15 \mathrm{~mm})$ of penetration per year (mpy) under these extreme environmental conditions, not representative of the real exposure of the fibers embedded in concrete. These values are of the same order of those found by Ismail et al. [68] 
in conventional $20 \mathrm{~mm}$-diameter steel bar used for concrete reinforcement, in which the corrosion rate obtained in similar conditions was $2.99 \mathrm{mpy}$. The recycled steel fibers showed similar performance regardless of their class, which means that the pre-treatment had little influence on the corrosion behavior of RSF. Therefore, the results suggest that the removal of the small amount of rubber debris from the fibers surface does not significantly affect the corrosion resistance of RSF.

It is worth to mention that it was very difficult to perform the electrochemical tests with the RSF of class 1 and 2, due to the non-uniformity of the fiber surface comparing with that of RSF of class 3 (as shown in SEM micrograph of Figures $1 \mathrm{c}$ and 4). Therefore, no accurate conclusions can be drawn regarding the effect of rubber debris in the corrosion behavior of RSF.

Regarding the tests of Series IV, the average mass loss that occurred in RSF due to non-induced corrosion was $3.54 \%(\mathrm{CoV}=59.86 \%)$, that is much higher than that of ISF, which was only $0.34 \%$ $(\mathrm{CoV}=27.26 \%)$. According to the values of $\mathrm{CoV}$, a much higher dispersion of the results was also obtained for RSF than for ISF, due to all the aspects already mentioned, namely, the irregular geometry and the non-uniform surface due to the attached rubber debris. Nevertheless, the difference of mass loss between RSF and ISF obtained after 7 days of chloride immersion (Series IV) and after the linear polarization tests (Table 5 - Series X for RSF) corroborates the results of $i_{\text {corr }}$ and $R_{p}$ obtained for these type of fibers.

The mass loss of RSF was larger in Series II due to the greater severity of the destructive potentiodynamic polarization test, where the applied potentials induced higher corrosion rates. In the linear polarization tests, the mass loss of RSF was similar between the different test Series for the same immersion time. In general, it was found a good correlation between the corrosion current density, $i_{c o r r}$, and the percentage of mass loss, which shows the validity of these tests. The RSF showed a greater increase of mass loss with the time of chloride immersion than ISF, except for Series IX where the mass loss was lower than expected, probably due to a higher initial adhesion of the corrosion products to RSF, which after 7 days of immersion was not observed. This greater increase of mass loss observed for RSF can be explained by the higher specific surface area of RSF in contact with the chloride solution $\left(1.28 \mathrm{~mm}^{2} / \mathrm{mg}\right)$ comparing with ISF $\left(0.55 \mathrm{~mm}^{2} / \mathrm{mg}\right)$, and the higher carbon content of RSF since an increase in the carbon content of steel increases the corrosion rate [69]. 


\subsection{SEM Fiber Analysis}

After the electrochemical tests, scanning electron microscopy (SEM) analysis were carried out in some fibers to analyse the effect of the corrosion action on their surface, in order to analyze the influence of corrosion in terms of surface configuration. SEM micrographs of non-corroded and corroded polished RSF are shown in Figures 17 and 18, respectively. The great effectiveness of the hand polishing performed to remove the rubber waste from the RSF surface is confirmed in Figure 17. The micrographs presented in Figure 18 show that the corrosion of RSF is generalized, forming a homogeneous layer of iron oxides in their surface.

Figure $18 \mathrm{~b}$ evidences the atomic contrast by backscattered electrons of chemical elements presented in the corrosive products. Through this micrograph, a chemical analysis was carried out to identify these elements. The main chemical elements identified were carbon, $\mathrm{C}$, oxygen, $\mathrm{O}$, and iron, $\mathrm{Fe}$, with the following composition in each zone: Z1 - 53.29\% O, 12.25\% C, 30.82\% Fe; Z2 - 23.25\% O, 23.98\% C, $48.01 \% \mathrm{Fe} ; \mathrm{Z3}-53.07 \% \mathrm{O}, 12.08 \% \mathrm{C}$, and $30.02 \% \mathrm{Fe}$. These elements were the result of the corrosion process, and when combined formed higher concentration of iron oxides in zones $Z 1$ and $Z 3$ due to the limited presence of oxygen in zone Z2 (23.25\%). It was also remarkable the presence of elements such as $\mathrm{Cu}$ and $\mathrm{Zn}$, which should be related with the brass coating commonly deposited on the top of the steel wire for tire cord to increase the adhesive bonding when is embedded in rubber. These elements showed greater atomic percentage in the class $1 \mathrm{RSF}(1.54 \%$ of $\mathrm{Cu}$ and $0.86 \%$ of $\mathrm{Zn}$, on average), which means that polishing (class 3 of RSF) was eventually able to remove part of the brass coating during the cleaning process (average of $1.19 \%$ of $\mathrm{Cu}$ and $0.64 \%$ of $\mathrm{Zn}$, on average).

The presence of corrosion products, along with the significant reduction of the fiber diameter, proves the severe damage occurred after the potentiodynamic polarization test (Figure 18a). The rough, irregular and porous appearance of the fiber surface, which confirms the presence of corrosion products, is also remarkable in the fibers that were subjected to linear polarization (Figure $18 \mathrm{~d}$ and 18f). After 7 days of chloride immersion, the release of accumulated products reveals the greater progress of the corrosion phenomenon (Figure 18e and 18f). 


\subsection{Splitting tensile tests under corrosion action}

After 10 days of chloride immersion, it was possible to observe corroded material in the $3.5 \% \mathrm{wt} . \mathrm{NaCl}$ solution and corrosion spots at exposed surfaces of the specimens.

Figure 19 shows the average splitting tensile stress $\left(\sigma_{t, \text { split }}\right)$ versus crack width curves, where $\sigma_{t, \text { split }}$ was determined from the following equation, as proposed by di Prisco et al. [41]:

$$
\sigma_{t, \text { split }}=\frac{0.89 \cdot P}{t \cdot h_{\text {lig }}}
$$

where $P$ is the compressive load, and $t$ is the thickness and $h_{\text {lig }}$ is the effective length of the notched region that defines the plan of failure. The nominal values for $t$ and $h_{\text {lig }}$ are equal to $50 \mathrm{~mm}$ and $130 \mathrm{~mm}$, respectively (Figure 5).

The crack width in X-axes corresponds to the average values measured by the five LVDTs shown in Figure 6. Note that the indicated crack widths were measured during the loading stage of the specimens.

For specimens of class $1 \mathrm{RSF}$, the corrosion action caused a slight decrease of the average stress at crack initiation (7.9\%) and the average post-cracking tensile strength (10.3\%). However, for RSF of class 2 and 3 , the corrosion action led to the increase of the average stress at crack initiation $(16.2 \%$ in class 2 and $26.2 \%$ in class 3$)$.

The reference specimens of class $1 \mathrm{RSF}$ showed the highest average stress at crack initiation (3.27 MPa) and the highest average post-cracking tensile strength $(3.40 \mathrm{MPa})$, which means that the two methods used to remove the small percentage of rubber from the fibers surface led to a decrease of the splitting tensile strength of the RSFRC specimens (Figure 19). It is also important to note that the RSF of class 1 used in reference specimens were mostly at the level of F3 and F4 of Fig. 12, with few rubber debris attached. Taking also into account the monotonic pullout tests in section 3.3, these results suggest that in specimens of class 2 RSF a significant amount of fibers had broken during the splitting tests. Considering also the dispersion of the pullout tests results represented in Fig. 13, it can be seen that RSF of class 1 (Fig.13a) can achieve a higher level of pullout load than RSF of class 2, which may justify the highest average splitting tensile stress showed by class 1 RSF.

The relevant conclusions taken from the stress versus crack opening relationships can be also confirmed 
by determining the residual strength parameters at a given crack width $\left(\sigma_{w^{*}}\right)$ and the respective energy due to fracture propagation up to w crack width $\left(G_{F^{*}}\right)$, which is represented by the area under the softening curve up to w crack width. The average values obtained are presented in Table 6.

From the results of non-corroded specimens it was found that the most effective fibers were those of class 1, followed by those of class 2 and 3. The corrosion of RSF apparently improved both splitting tensile strength and toughness of concrete specimens reinforced with RSF of classes 2 and 3 . However, the splitting tensile strength was only little affected by the corrosion of class 1 RSF. One reason may be related to the lower level of fiber corrosion found in these specimens with class 1 RSF. These results corroborate with the results obtained in the linear polarization tests after 7 days of immersion (Series VI, VIII and X).

\section{CONCLUSIONS}

This research article summarizes the experimental work carried out to characterize the corrosion resistance of RSF by means of electrochemical monitoring techniques and scanning electron microscopy (SEM) analysis, and to evaluate the corrosion effects on the post-cracking behavior of RSFRC by performing double edge wedge splitting tests (DEWST). To remove the rubber debris attached to the RSF surface derived from the tire recycling process two distinct methods were adopted: hand polishing and submitting to high temperatures. The effect of these pre-treatment methods in the micro-mechanical properties of RSF was evaluated by performing Nano-indentation tests. The adhesive bond between the RSF and the surrounding SCC matrix was analyzed by performing monotonic RSF pullout tests.

When compared to ISF, the RSF are more complex and heterogeneous in terms of its microstructure, showing the RSF higher hardness values due to the higher carbon content. Additionally, due to its high carbon content, the RSF preserves some retained austenite in the microstructure. Contrary to what was observed in ISF, the heating of RSF at $350^{\circ} \mathrm{C}$ slightly increased the hardness of this fiber, probably due to the transformation of retained austenite into bainite, which may have a negative effect on the durability.

The rubber content attached to the RSF surface can lead to a decrease of the pullout load if the amount of rubber covers a significant area of the fiber surface. The fiber shape of the embedded length has a significant influence in the fiber pullout behavior, since the more irregular and twisted it is, the higher the fiber pullout load 
and the greater the probability of fiber rupture.

Based on electrochemical measurements, the corrosion probability of RSF immersed in a $3.5 \%$ wt. $\mathrm{NaCl}$ solution is higher than $90 \%$. The polarization curves showed that the corrosion of RSF is generalized in its surface, and it seems that the RSF are slightly more susceptible to corrosion that ISF. The small rubber debris attached to RSF surface had a negligible influence in terms of fiber corrosion resistance, so that from this point of view the pre-treatment methods used to clean RSF may be dispensed.

The SEM analysis of corroded RSF confirmed that corrosion was uniform on the entire fiber surface and reveals the greater progress of the corrosion phenomenon with the immersion time. The main corrosion products were iron oxides and were also detected $\mathrm{Cu}$ and $\mathrm{Zn}$, probably from the brass coating existing on the original tire steel.

After 10 days of chloride immersion, a slight decrease of the average post-cracking tensile strength was observed in the concrete specimens reinforced with reference RSF (as were received). All the RSFRC specimens submitted to chloride immersion showed similar post-cracking behavior which means that the small percentage of rubber attached to fibers surface has a negligible effect in the corrosion resistance of RSFRC.

\section{ACKNOWLEDGEMENTS}

The authors would like to express their sincere gratitude and appreciation to Twincon Company for supplying the recycled steel fibers. The authors wish also to acknowledge the support provided by CiviTest Company and the Scientific and Technological Research Assistance Centre (CACTI) of the University of Vigo. The first author would like to thank the FCT for the financial support through the Research Grant PD/BD/113638/2015. The third author acknowledges the grant SFRH/BSAB/114302/2016 provided by FCT. Part of this work is supported by FCT with the reference project UID/EEA/04436/2013, COMPETE 2020 with the code POCI-010145-FEDER-006941. Finally the support of the FCT through the project PTDC/ECM-EST/2635/2014 is acknowledged.

\section{REFERENCES}

[1] Pilakoutas K., Neocleous K., Tlemat H. (2004). Reuse of tyre steel fibers as concrete reinforcement. Proceedings of the ICE: Engineering Sustainability, V. 157(3), pp. 131-138; 
[2] Pilakoutas, K. \& Strube, R. (2001). Re-use of tyre fibres in concrete. International Symposium Recycling and Re-use of used tyres, Dundee, Thomas Telford, pp. 225-236;

[3] Leone, M., Centonze, G., Colonna, D., Micelli, F., Aiello, M.A. (2016). Experimental Study on Bond Behavior in Fiber-Reinforced Concrete with Low Content of Recycled Steel Fiber. Journal of Materials in Civil Engineering, ASCE, ISSN 0899-1561, pp. 1-13;

[4] Tlemat, H., Pilakoutas, K., Neocleous, K. (2004). Demonstrating steel fibres from waste tyres as reinforcement in concrete: material characterization. Proceedings of the 1st International Conference on Innovative Materials and Technologies for Construction and Restoration, 7-9 June, Lecce, Italy;

[5] Zamanzadeh, Z., Lourenço, L.A.P., Barros, J.A.O. (2015). Recycled Steel Fibre Reinforced Concrete failing in bending and in shear. Construction and Building Materials, V. 85, pp. 195-207;

[6] Barros, J., Zamanzadeh, Z., Mendes, P.J.D., Lourenço, L.A.P. (2013). Assessment of the potentialities of recycled steel fibres for the reinforcement of cement based materials. 3rd Workshop on "The new boundaries of structural concrete: Session C - New Scenarios for Concrete", ACI IC - Bergamo;

[7] Micelli, F., Leone, M., Centonze, G., Aiello, M. (2014). Chapter: Go Green: Using Waste and Recycling Materials, Infrastructure Corrosion and Durability Sustainability Study, Edited by Yang Lu, OMICS Group eBooks, USA;

[8] Centonze G., Leonard M., Aiello M.A. (2012). Steel fibers from waste tires as reinforcement in concrete: A mechanical characterization. Construction and Building Materials, V. 36, pp. 12-57;

[9] Aiello M.A., Leuzzi F., Centonze G., Maffezzoli A. (2009). Use of steel fibers recovered from waste tyres as reinforcement in concrete: Pull-out behaviour, compressive and flexural strength. Waste Management, V. 29, pp. 1960-1970;

[10] Tlemat, H., Pilakoutas, K., Neocleous, K. (2005). Stress-strain characteristic of SFRC using recycled fibres. Material and Structures, V. 39, pp. 365-376;

[11] Tlemat, H., Pilakoutas, K., Neocleous, K. (2003). Flexural toughness of SFRC made with fibres extracted from tyres. Recycling and Reuse of Waste Materials, Proceedings of International Symposium on Advances in Waste Management and Recycling, Dundee, 9-11 September, Pub. Thomas Telford Ltd.;

[12] Neocleous, K., Tlemat, H., Pilakoutas, K. (2006). Design issues for concrete reinforced with steel fibers, including fibers recovered from used tires, Journal of Materials in Civil Engineering, V.18 (5), pp. 677-685;

[13] Graeff, A., Pilakoutas, K., Lynsdale, C., Neocleous, K., Peres, M. (2012). Fatigue resistance and 
cracking mechanism of concrete pavements reinforced with recycled steel fibres recovered from postconsumer tyres, Engineering Structures, V. 45, pp. 385-395;

[14] Abrishambaf, A., Barros, J.A.O., Cunha, V.M.C.F., Frazão, C. (2017). Time dependent behaviour of fibre pull-out in self-compacting concrete. Cement and Concrete Composites. V. 77, pp. 14-28;

[15] ACI 544.5R-10 (2010). Report on the physical properties and durability of fiber-reinforced concrete. ACl Committee 544;

[16] Bentur, A. \& Mindess, S. (2007). Fibre reinforced cementitious composites. 2ed. London, Taylor \& Francis;

[17] Granju, J., Balouch, S. (2005). Corrosion of steel fibre reinforced concrete from the cracks. Cement and Concrete Research, V. 35(3), pp. 572-577;

[18] Balouch, S., Forth, J., Granju, J. (2010). Surface corrosion of steel fibre reinforced concrete. Cement and Concrete Research, V.17, pp. 410-414;

[19] Singh, A., Singhal, D. (2011). Permeability of steel fibre reinforced concrete influence of fibre parameters. Procedia Engineering, V. 14, pp. 2823-2829;

[20] Frazão, C., Camões, A., Barros, J., Gonçalves, D. (2015). Durability of steel fiber reinforced selfcompacting concrete. Construction and Building Materials, V. 80, pp. 155-166;

[21] Frazão, C.M.V., Barros, J.A.O., Camões, A.F.L.L., Alves, A., Rocha, L. (2016). Corrosion effects on pullout behavior of hooked steel fibers in self-compacting concrete. Cement and Concrete Research, V. 79, pp. 112-122;

[22] Chen, G., Hadi, M.N.S., Gao, D., Zhao, L. (2015). Experimental study on the properties of corroded steel fibres. Construction and Building Materials, V. 79, pp. 165-172;

[23] Solgaard, A., Kuter, A., Edvardsen, C., Stang, H., Geiker, M. (2010). Durability Aspects of Steel Fibre Reinforced Concrete in Civil Infrastructure. Proc. 2nd International Symposium on Service Life Design for Infrastructure, 4th - 6th October, Delft, The Netherlands;

[24] RILEM TC 162-TDF (2003). Test and design methods for steel fibre reinforced concrete. $\sigma$-e-design method. Final Recommendation. Materials and Structures, V. 36, pp. 560-567;

[25] Berrocal, C., Lundgren, K., LÖfgren, I. (2013). Influence of steel fibres on corrosion of reinforcement in concrete in chloride environments: A review. In: Proceedings of International Conference: FC2013-Fiber Concrete 2013, 12th-13th September, Prague, Czech Republic;

[26] Sadeghi-Pouya, H., Ganjian, E., Claisse, P., Muthuramalingam, K. (2013). Corrosion durability of high 
performance steel fibre reinforced concrete. Proceedings of 3rd International Conference on Sustainable Construction Materials and Technologies, Japan Concrete Institute, Kyoto, Japan;

[27] Berrocal, C. G., Lundgren, K., Löfgren I. (2015). Corrosion of steel bars embedded in fibre reinforced concrete under chloride attack: State of the art. Cement and Concrete Research, V. 80, pp. 69-85;

[28] Berrocal, C. G. (2015). Chloride Induced Corrosion of Steel Bars in Fibre Reinforced Concrete. Thesis for the degree of licentiate of engineering, Department of Civil and Environmental Engineering, CHALMERS UNIVERSITY OF TECHNOLOGY, Goteborg, Sweden;

[29] Shi, X., Xie, N., Fortune, K., Gong, J. (2012). Durability of steel reinforced concrete in chloride environments: An overview. Construction and Building Materials, V. 30, pp. 125-138;

[30] Yoon, I. (2012). Chloride Penetration through Cracks in High- Performance Concrete and Surface Treatment System for Crack Healing. Hindawi Publishing Corporation, Advances in Materials Science and Engineering, Article ID 294571, 8 pp.;

[31] Nordstrom, E. (2005). Durability of Sprayed Concrete - Steel fibre corrosion in cracks. Doctoral Thesis, Department of Civil and Environmental Engineering, Division of Structural Engineering, Luleå University of Technology, Sweden;

[32] Corinaldesi, V., Moriconi, G. (2004). Durable fiber reinforced self-compacting concrete. Cement and Concrete Research, V. 34, pp. 249-254;

[33] Graeff, A., Pilakoutas, K., Lynsdale, C., Neocleous, K. (2009). Corrosion Durability of Recycled Steel Fibre Reinforced Concrete. Article No.7, Intersections/Intersec_ii, V. 6, No.4;

[34] Tsai, C., Li, L., Chang, C., Hwang, C.(2009). Durability Design and Application of Steel Fiber Reinforced Concrete in Taiwan. Arabian Journal for Science and Engineering, V. 34, Number 1B;

[35] Michel, A., Geiker, M., Stang, H., Olesen, J., Solgaard, A. (2009). Numerical modelling of reinforcement corrosion, influence of steel fibres and moisture content on resistivity and corrosion current density. Proc. 3th International RILEM PhD Student Workshop on Modelling the Durability of Reinforced Concrete, 22th - 24th October, Guimarães, Portugal;

[36] Nemegeer, D., Vanbrabant, J., Stang, H. (2003). Brite-Euram Program on Steel Fibre Concrete, Durability Corrosion Resistance of Cracked Fibre-Reinforced Concrete. Test and Design Methods for Steel Fibre Reinforced Concrete-Background and Experiences. B. Schnütgen and L. Vandewalle, eds., RILEM Technical Committee 162, TDF Workshop, Proceedings Pro 31, pp. 47-66;

[37] Waweru, R. (2011). The effect of fiber corrosion on shear capacity of steel fiber reinforced concrete 
beams and an initial investigation on alkali-silica reaction in steel fiber reinforced concrete. Master Thesis in Civil Engineering, University of Texas at Arlington;

[38] Alizade, E., Jandaghi Alaee, F., Zabihi, S. (2016). Effect of steel fiber corrosion on mechanical properties of steel fiber reinforced concrete. Asian Journal of Civil Engineering, V. 17, No. 2, pp. 147-158;

[39] Graeff, A.G., Pilakoutas, K., Neocleous, K., Lynsdale, C. (2011). Behaviour of concrete reinforced with recycled steel fibres exposed to chloride contaminated environment. Proceedings of 6 th International Conference Fibre Concrete 2011, 8-9 September, Prague, Czech Republic;

[40] Lameiras, R., Barros, J., Azenha, M. (2015). Influence of casting condition on the anisotropy of the fracture properties of Steel Fibre Reinforced Self-Compacting Concrete (SFRSCC). Cement \& Concrete Composites, V. 59, pp. 60-76;

[41] di Prisco, M., Ferrara, L., Lamperti, M.L. (2013). Double edge wedge splitting (DEWS): an indirect tension test to identify post-cracking behaviour of fibre reinforced cementitious composites. Materials and Structures, V. 46 (11), pp. 1893-1918;

[42] Abrishambaf, A., Barros, J.A.O., Cunha, V.M.C.F. (2015). Tensile stress-crack width law for steel fibre reinforced self-compacting concrete obtained from indirect (splitting) tensile tests. Cement \& Concrete Composites, V. 57, pp. 153-165;

[43] Abrishambaf, A, Barros, JAO, Cunha, VMCF (2013). Relation between fibre distribution and postcracking behaviour in steel fibre reinforced self-compacting concrete panels. Cement and Concrete Research, V. 51, pp. 57-66;

[44] Barros, J., Pereira, E., Santos, S. (2007). Lightweight panels of steel fibre reinforced self-compacting concrete. Journal of Materials in Civil Engineering, V. 19(4), pp. 295-304;

[45] EFNARC. (2005). The European guidelines for self-compacting concrete;

[46] EN 12390-3 (2009). Testing hardened concrete - Part 3: compressive strength of specimens;

[47] LNEC E397 (1993). Concrete. Determination of the modulus of elasticity under compression, Lisbon: LNEC, p. 2;

[48] Abrishambaf, A. (2015). Creep Behaviour of Cracked Steel Fibre Reinforced Self-Compacting Concrete Laminar Structures. PhD Thesis. University of Minho, Portugal;

[49] Cunha, V.M.C.F., Barros, J.A.O., Sena-Cruz, J.M. (2011). An integrated approach for modelling the tensile behaviour of steel fibre reinforced self-compacting concrete. Cement and Concrete Research, V. 41, pp. 64-76; 

Germany, 2013;

[51] EN 12350-8. Testing fresh concrete - Part 8: Self-Compacting Concrete - Slump-flow test (2010);

[52] NP EN 206-1 (2007). Concrete - Part 1: Specification, performance, production and conformity. IPQ, Lisbon, pp. 21;

[53] Baldenebro-Lopez, F.J., Gomez-Esparza, C.D., Corral-Higuera, R., Arredondo-Rea S.P., PellegriniCervantes, M.J., Ledezma-Sillas, J. E., Martinez-Sanchez, R., Herrera-Ramirez, J.M. (2015). Influence of Size on the Microstructure and Mechanical Properties of an AISI 304L Stainless Steel - A Comparison between Bulk and Fibers, Materials, V. 8, pp. 451-461;

[54] Thelning, K.-E. (2013). Steel and its Heat Treatment. Butterworth Heinemann, $2^{\text {nd }}$ Edition, pp. 696;

[55] Krauss, G. (2015). Steels: Processing, structure, and performance, $2^{\text {nd }}$ Edition, ASM International;

[56] Krauss, G. (1999). Martensite in steel: strength and structure. Materials Science and Engineering, V.A273-275, pp. 40-57;

[57] Schade, C., Murphy, T., Lawley, A., Doherty, R. (2016). Microstructure and Mechanical properties of a Bainitic Powder Metallurgy Steel. International Journal of Powder Metallurgy. V. 52, Issue 2, pp. 37-46;

[58] Callister, W.D., Rethwisch, D.G. (2007). Materials Science and Engineering: An Introduction, 8th Edition, John Wiley \& Sons, Inc.

[59] Mertinger, V., Nagy, E., Tranta, F., Sólyom, J. (2008). Strain-induced martensitic transformation in textured austenitic stainless steels. Materials Science and Engineering A, 481-482, pp. 718-722;

[60] Chen, Z., Gandhi, U., Lee, J., Wagoner, R. H. (2016). Variation and consistency of Young's modulus in steel. Journal of Materials Processing Technology 227, V 227, pp. 227-243;

[61] Moosbrugger, C., (Ed) (2002). Atlas of stress-strain curves. $2^{\text {nd }}$ Edition, ASM International, pp. 67-92;

[62] ASTM C876-09 (2009). Standard Test Method for Corrosion Potentials of Uncoated Reinforcing Steel in Concrete. ASTM International;

[63] Freire, L., Nóvoa, X.R., Pena, G., Vivier, V. (2008). On the corrosion mechanism of AISI 204Cu stainless steel in chlorinated alkaline media. Corrosion Science, V. 50, pp. 3205-3212;

[64] Koç, E., Kannan, M.B., Ünal, M., Candan, E. (2015). Influence of zinc on the microstructure, mechanical properties and in vitro corrosion behavior of magnesium-zinc binary alloys. Journal of Alloys and Compounds, V. 648, pp. 291-296;

[65] Wolynec, S., Electrochemical Techniques in Corrosion, Edusp - Publisher of University of São Paulo, 
São Paulo, Brasil (2003) [Portuguese];

[66] Alonso, C., Andrade C. (1990). Effect of nitride as a corrosion inhibitor in contaminated and chloridefree carbonated mortars. ACI Materials Journal, V. 87 (2), pp. 130-137;

[67] González, J., Miranda, J., Feliu, S. (2004). Considerations on reproducibility of potential and corrosion rate measurements in reinforced concrete. Corrosion Science, V. 46, pp. 2467-2485;

[68] Ismail, M., Hamzah, E., Chun Guan, G., Abd Rahman, I. (2010). Corrosion performance of dualphase steel embedded in concrete. Arabian Journal for Science and Engineering, V.35, № 2B, pp. 8190 ;

[69] Pleshivtsev, V. G., Filippov, G. A., Pak, Y. A., Livanova, O. V. (2009). Effect of carbon content and stressed state on the corrosion rate of pipe steel in heating systems. Metallurgist, V. 53, pp. 502-505; 
Table $1-$ Mix design for $1 \mathrm{~m}^{3}$ of SCC and RSFRC

\begin{tabular}{ccccccccccc} 
& $\mathbf{C}(\mathbf{k g})$ & $\mathbf{L F}(\mathbf{k g})$ & $\mathbf{F S}(\mathbf{k g})$ & $\mathbf{C S}(\mathbf{k g})$ & $\mathbf{C A}(\mathbf{k g})$ & $\mathbf{W}(\mathbf{L})$ & $\mathbf{S P}(\mathbf{L})$ & $\mathbf{V M A}(\mathbf{k g})$ & $\mathbf{W} / \mathbf{C}$ & $\mathbf{C f}(\mathbf{k g})$ \\
\hline SCC & 380.6 & 326.2 & 368.2 & 568.0 & 510.0 & 158.2 & 8.6 & 0.3 & 0.42 & - \\
\hline RSFRC & 380.5 & 353.0 & 237.0 & 710.0 & 590.0 & 140.0 & 7.8 & - & 0.37 & 60 \\
\hline
\end{tabular}

Table 2 - Experimental program of electrochemical tests

\begin{tabular}{|c|c|c|c|}
\hline Series & RSF pre-treatment & Chloride immersion & Procedure \\
\hline 1 & $\begin{array}{c}\text { Class } 1 \\
\text { (Reference) }\end{array}$ & 60 minutes & $\mathrm{OCP} \rightarrow$ Cyclic Polarization \\
\hline II & \multirow{3}{*}{$\begin{array}{l}\text { Class } 3 \\
\text { (Polished) }\end{array}$} & 60 minutes & \multirow{2}{*}{$\mathrm{OCP} \rightarrow$ Potentiodynamic Polarization } \\
\hline III & & 7 days & \\
\hline IV & & 7 days & Weighing fibers \\
\hline $\mathrm{V}$ & \multirow{2}{*}{$\begin{array}{c}\text { Class } 1 \\
\text { (Reference) }\end{array}$} & 30 minutes & \multirow{6}{*}{ OCP $\rightarrow$ Linear Polarization } \\
\hline VI & & 7 days & \\
\hline VII & \multirow{2}{*}{$\begin{array}{c}\text { Class } 2 \\
\text { (submitted to } \mathrm{T}=350^{\circ} \mathrm{C} \text { ) }\end{array}$} & 30 minutes & \\
\hline VIII & & 7 days & \\
\hline IX & \multirow{2}{*}{$\begin{array}{l}\text { Class } 3 \\
\text { (Polished) }\end{array}$} & 30 minutes & \\
\hline$X$ & & 7 days & \\
\hline
\end{tabular}

Table 3 - Average values (and standard deviation) of Young's modulus and hardness obtained by nanoindentation tests

\begin{tabular}{|c|c|c|c|c|}
\hline & Fibers & $\begin{array}{l}\text { Young's modulus } \\
\text { (GPa) }\end{array}$ & $\begin{array}{l}\text { Hardness } \\
\text { (GPa) }\end{array}$ & $\begin{array}{l}\text { Number of } \\
\text { indentations }\end{array}$ \\
\hline \multirow{3}{*}{$\begin{array}{l}\text { 岕 } \\
\widetilde{x}\end{array}$} & Class 1 (REF) & $131.967(47.916)$ & $6.407(1.096)$ & 37 \\
\hline & Class $2\left(350^{\circ} \mathrm{C}\right)$ & $193.828(46.773)$ & 7.262 (0.954) & 41 \\
\hline & Class 3 (Polished) & $200.860(9.026)$ & $9.159(0.373)$ & 359 \\
\hline \multirow{2}{*}{$\underline{\underline{\omega}}$} & Class 1 (REF) & $\mathbf{2 1 2 . 7 6 6 ~ ( 1 2 . 2 2 3 ) ~}$ & $4.098(0.197)$ & 36 \\
\hline & Class $2\left(350^{\circ} \mathrm{C}\right)$ & $192.943(17.362)$ & 2.937 (0.238) & 30 \\
\hline
\end{tabular}


Table 4 - Results obtained in the potentiodynamic polarization tests

\begin{tabular}{|c|c|c|c|c|c|c|}
\hline & & & $E_{(i=0)}(\mathrm{mV})$ & $i_{c o r r}\left(\mu \mathrm{A} / \mathrm{cm}^{2}\right)$ & $R_{p}\left(\mathrm{k} \Omega / \mathrm{cm}^{2}\right)$ & $\begin{array}{c}\text { Mass loss } \\
(\%)\end{array}$ \\
\hline \multirow{2}{*}{$\begin{array}{l}\text { Series II } \\
\text { (30 min) }\end{array}$} & \multirow{2}{*}{$\begin{array}{c}\text { Class } 3 \text { RSF } \\
\text { (Polished) }\end{array}$} & $A v g \pm S t D$ & $-479.6 \pm 11.4$ & $15.567 \pm 3.430$ & $0.646 \pm 0.563$ & 26.48 \\
\hline & & CoV $(\%)$ & 2.37 & 22.03 & 87.06 & 27.91 \\
\hline \multirow{2}{*}{\multicolumn{2}{|c|}{ Class 1 ISF (30 min) }} & $A v g \pm S t D$ & $-573.5 \pm 7.5$ & $10.933 \pm 6.490$ & $0.871 \pm 0.255$ & 26.47 \\
\hline & & $\operatorname{CoV}(\%)$ & 1.31 & 59.37 & 29.29 & 16.25 \\
\hline \multirow{2}{*}{$\begin{array}{l}\text { Series III } \\
\text { (7 days) }\end{array}$} & \multirow{2}{*}{$\begin{array}{c}\text { Class } 3 \text { RSF } \\
\text { (Polished) }\end{array}$} & $A v g \pm S t D$ & $-603.8 \pm 17.6$ & $20.051 \pm 12.991$ & $2.161 \pm 1.795$ & - \\
\hline & & $\operatorname{CoV}(\%)$ & 2.92 & 64.79 & 83.09 & - \\
\hline \multirow{2}{*}{\multicolumn{2}{|c|}{ Class 1 ISF (7 days) }} & $A v g \pm S t D$ & $-711.3 \pm 15.5$ & $9.659 \pm 1.082$ & $4.011 \pm 2.878$ & - \\
\hline & & CoV (\%) & 2.19 & 11.20 & 71.74 & - \\
\hline
\end{tabular}

Table 5 - Results obtained in the linear polarization tests

\begin{tabular}{|c|c|c|c|c|c|c|c|}
\hline & & & \\
\hline & & & $E_{(i=0)}(\mathrm{mV})$ & $i_{c o r r}\left(\mu \mathrm{A} / \mathrm{cm}^{2}\right)$ & $R_{p}\left(\mathrm{k} \Omega / \mathrm{cm}^{2}\right)$ & $\begin{array}{c}\text { Mass loss } \\
(\%)\end{array}$ & $\begin{array}{l}\text { Corrosion } \\
\text { rate (mpy) }\end{array}$ \\
\hline \multirow{2}{*}{$\begin{array}{l}\text { Series V } \\
(30 \text { min) }\end{array}$} & \multirow{2}{*}{$\begin{array}{l}\text { Class } 1 \text { RSF } \\
\text { (Reference) }\end{array}$} & $A v g \pm S t D$ & $-525.4 \pm 5.2$ & $8.679 \pm 1.764$ & $0.609 \pm 0.030$ & 1.63 & $4.009 \pm 0.815$ \\
\hline & & $\operatorname{CoV}(\%)$ & 0.99 & 20.33 & 4.98 & 60.25 & 20.33 \\
\hline \multirow{2}{*}{$\begin{array}{l}\text { Series VII } \\
(30 \mathrm{~min})\end{array}$} & \multirow{2}{*}{$\begin{array}{c}\text { Class } 2 \text { RSF } \\
\left(\mathrm{T}=350^{\circ} \mathrm{C}\right)\end{array}$} & $A v g \pm S t D$ & $-468.6 \pm 13.0$ & $12.937 \pm 1.477$ & $0.683 \pm 0.153$ & 1.39 & $5.975 \pm 0.682$ \\
\hline & & $\operatorname{CoV}(\%)$ & 2.77 & 11.42 & 22.45 & 54.20 & 11.42 \\
\hline \multirow{2}{*}{$\begin{array}{l}\text { Series IX } \\
(30 \mathrm{~min})\end{array}$} & \multirow{2}{*}{$\begin{array}{c}\text { Class } 3 \text { RSF } \\
\text { (Polished) }\end{array}$} & $A v g \pm S t D$ & $-493.8 \pm 22.5$ & $7.077 \pm 1.751$ & $0.778 \pm 0.104$ & 0.48 & $3.268 \pm 0.809$ \\
\hline & & CoV (\%) & 4.55 & 24.74 & 13.43 & 35.76 & 24.74 \\
\hline \multirow{2}{*}{\multicolumn{2}{|c|}{ Class 1 ISF (30 min) }} & $A v g \pm S t D$ & $-566.5 \pm 4.5$ & $3.738 \pm 0.627$ & $1.383 \pm 0.123$ & 0.50 & $1.727 \pm 0.290$ \\
\hline & & $\operatorname{CoV}(\%)$ & 0.80 & 16.77 & 8.93 & 20.99 & 16.77 \\
\hline \multirow{2}{*}{$\begin{array}{l}\text { Series VI } \\
\text { (7 days) }\end{array}$} & \multirow{2}{*}{$\begin{array}{l}\text { Class } 1 \text { RSF } \\
\text { (Reference) }\end{array}$} & $A v g \pm S t D$ & $-631.1 \pm 2.2$ & $8.043 \pm 1.969$ & $1.074 \pm 0.270$ & 2.93 & $3.715 \pm 0.909$ \\
\hline & & $\operatorname{CoV}(\%)$ & 0.35 & 24.48 & 25.14 & 28.94 & 24.48 \\
\hline \multirow{2}{*}{$\begin{array}{l}\text { Series VIII } \\
\text { (7 days) }\end{array}$} & \multirow{2}{*}{$\begin{array}{c}\text { Class } 2 \text { RSF } \\
\left(\mathrm{T}=350^{\circ} \mathrm{C}\right)\end{array}$} & $A v g \pm S t D$ & $-605.8 \pm 34.3$ & $9.749 \pm 1.877$ & $1.381 \pm 0.667$ & 3.46 & $4.905 \pm 0.730$ \\
\hline & & CoV (\%) & 5.64 & 19.26 & 28.33 & 40.94 & 14.88 \\
\hline \multirow{2}{*}{$\begin{array}{l}\text { Series X } \\
\text { (7 days) }\end{array}$} & \multirow{2}{*}{$\begin{array}{c}\text { Class } 3 \text { RSF } \\
\text { (Polished) }\end{array}$} & $A v g \pm S t D$ & $-609.1 \pm 3.8$ & $11.198 \pm 3.298$ & $0.548 \pm 0.162$ & 3.63 & $5.172 \pm 1.523$ \\
\hline & & CoV $(\%)$ & 0.63 & 29.45 & 29.52 & 40.16 & 29.45 \\
\hline \multirow{2}{*}{\multicolumn{2}{|c|}{ Class 1 ISF (7 days) }} & $A v g \pm S t D$ & $-677.5 \pm 21.7$ & $3.677 \pm 0.995$ & $1.207 \pm 0.047$ & 0.69 & $1.698 \pm 0.398$ \\
\hline & & $\operatorname{CoV}(\%)$ & 3.20 & 27.06 & 3.88 & 32.79 & 23.43 \\
\hline
\end{tabular}


Table 6 - Maximum stress, residual stress and energy due to fracture propagation

\begin{tabular}{|c|c|c|c|c|c|c|c|c|c|c|c|c|}
\hline \multirow{2}{*}{$\begin{array}{l}\text { RSF } \\
\text { Class }\end{array}$} & & $\sigma_{\operatorname{máx}}$ & $\sigma_{0.3}$ & $\sigma_{0.5}$ & $\sigma_{1.0}$ & $\sigma_{1.5}$ & $\sigma_{3.0}$ & $G_{F 0.3}$ & $G_{F 0.5}$ & $G_{F 1.0}$ & $G_{F 1.5}$ & $G_{F 3.0}$ \\
\hline & & [MPa] & [MPa] & [MPa] & [MPa] & [MPa] & [MPa] & {$[\mathrm{N} / \mathrm{mm}]$} & {$[\mathrm{N} / \mathrm{mm}]$} & {$[\mathrm{N} / \mathrm{mm}]$} & {$[\mathrm{N} / \mathrm{mm}]$} & {$[\mathrm{N} / \mathrm{mm}]$} \\
\hline \multirow{2}{*}{ 1-REF } & Avg & 3.59 & 3.08 & 2.70 & 1.98 & 1.63 & 0.79 & 0.97 & 1.56 & 2.70 & 3.59 & 5.14 \\
\hline & $\operatorname{CoV}(\%)$ & 13.77 & 14.56 & 13.44 & 23.95 & 26.12 & 30.37 & 12.34 & 12.80 & 15.49 & 18.11 & 23.93 \\
\hline \multirow{2}{*}{ 1-COR } & Avg & 3.19 & 2.82 & 2.39 & 1.73 & 1.29 & 0.73 & 0.88 & 1.40 & 2.41 & 3.16 & 5.18 \\
\hline & $\operatorname{CoV}(\%)$ & 20.47 & 33.64 & 40.68 & 45.69 & 44.78 & 28.65 & 27.86 & 31.21 & 35.88 & 38.17 & 27.58 \\
\hline \multirow{2}{*}{ 2-REF } & Avg & 2.73 & 2.20 & 1.79 & 1.28 & 0.88 & 0.57 & 0.75 & 1.15 & 1.91 & 2.45 & 3.65 \\
\hline & CoV (\%) & 15.24 & 12.54 & 7.79 & 12.15 & 21.16 & 17.14 & 14.79 & 12.68 & 11.12 & 10.97 & 3.59 \\
\hline \multirow{2}{*}{ 2-COR } & Avg & 3.41 & 2.56 & 2.25 & 1.47 & 1.10 & 0.59 & 0.86 & 1.34 & 2.27 & 2.91 & 4.60 \\
\hline & $\operatorname{CoV}(\%)$ & 40.89 & 63.65 & 70.89 & 76.55 & 74.76 & 55.11 & 50.61 & 56.92 & 64.07 & 66.52 & 65.48 \\
\hline \multirow{2}{*}{ 3-REF } & Avg & 2.28 & 2.04 & 1.85 & 1.39 & 1.16 & 0.77 & 0.64 & 1.03 & 1.84 & 2.47 & 3.83 \\
\hline & CoV (\%) & 8.56 & 8.68 & 12.53 & 23.98 & 34.15 & 47.40 & 8.58 & 8.92 & 12.45 & 16.89 & 23.72 \\
\hline \multirow{2}{*}{ 3-COR } & Avg & 2.94 & 2.71 & 2.49 & 1.91 & 1.51 & 0.84 & 0.82 & 1.34 & 2.43 & 3.28 & 4.94 \\
\hline & $\operatorname{CoV}(\%)$ & 24.55 & 32.74 & 36.26 & 44.44 & 49.93 & 47.69 & 27.82 & 30.62 & 34.70 & 37.77 & 40.84 \\
\hline
\end{tabular}




\section{APPENDIX B - FIGURES}

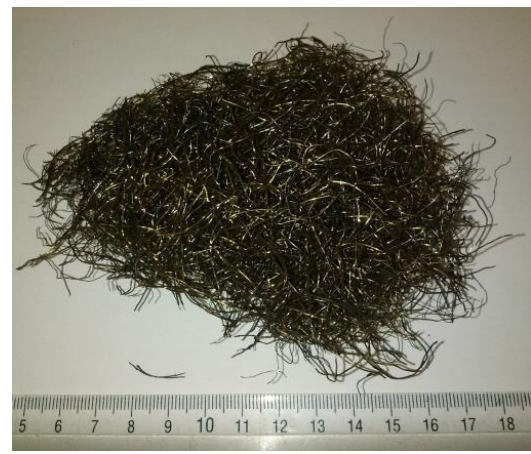

(a)

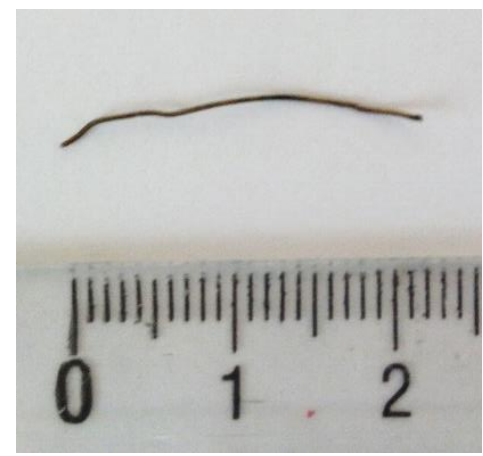

(b)

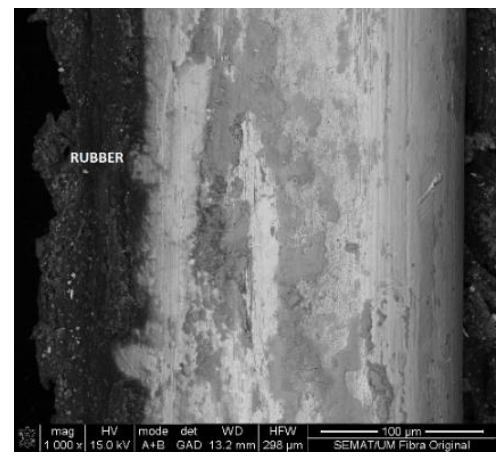

(c)

Figure 1 - Recycled steel fibers: (a) general view of multi fibers (b) general view of the geometry of a single RSF (c) SEM micrograph of the surface of a single RSF (Reference)

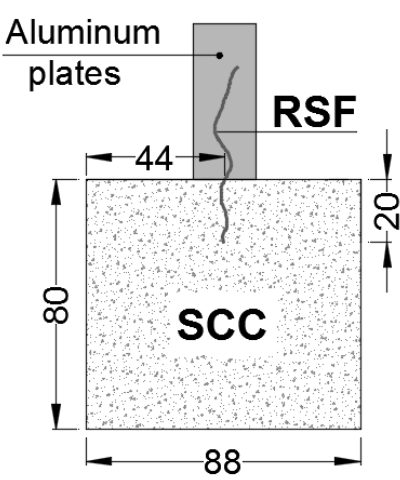

(a)

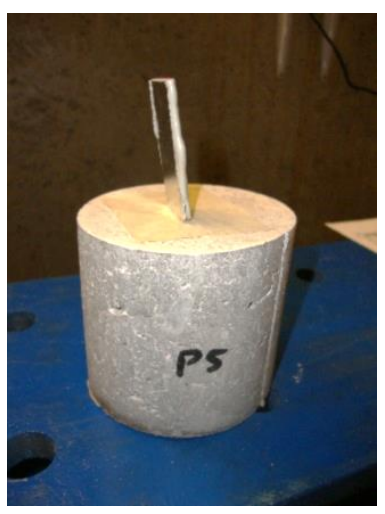

(b)

Figure 2 - Pullout SCC specimen

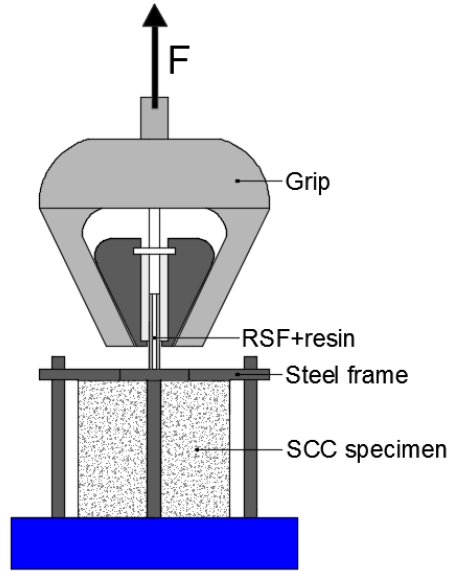

(a)

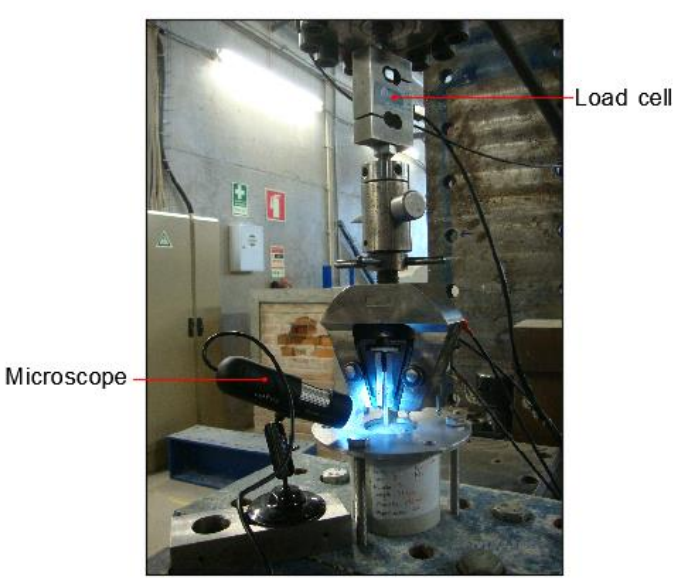

(b) 


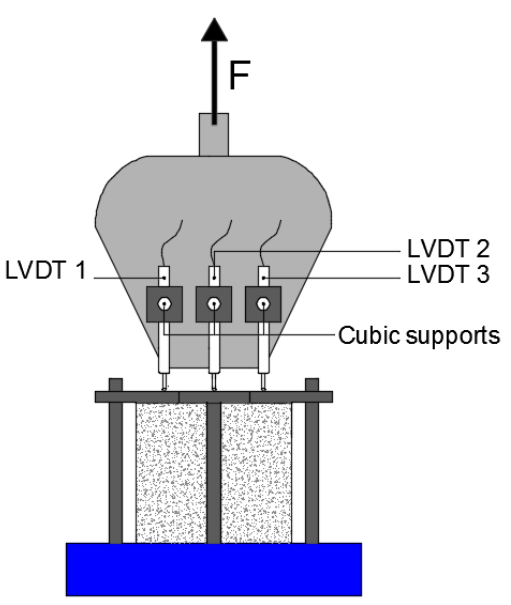

(c)

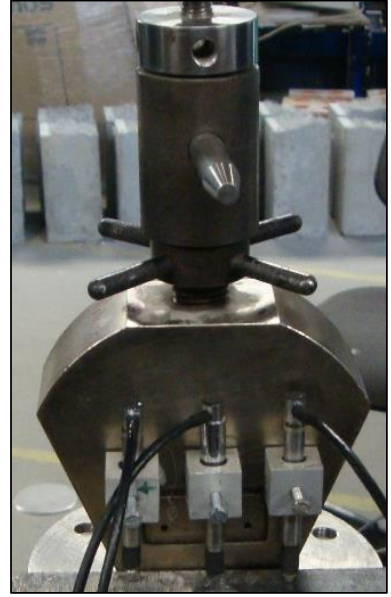

(d)

Figure 3 - Test setup for fiber pullout tests [43] (a) (b) Specimen front view (c) (d) Specimen back view

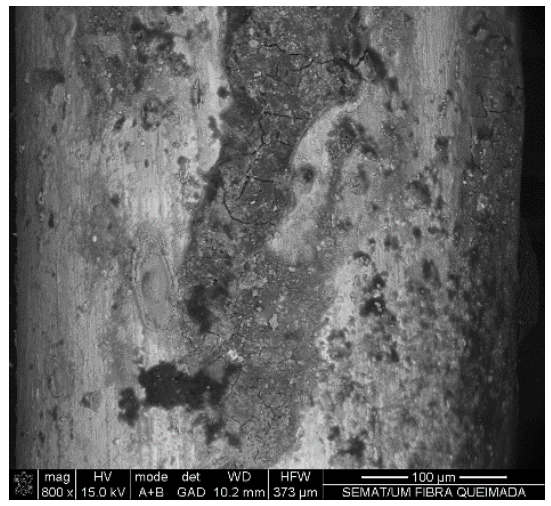

(a)

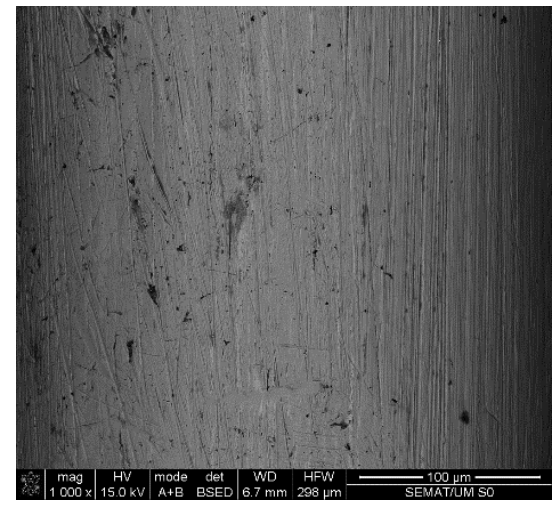

(b)

Figure 4 - SEM micrographs of the surface of a single RSF of: (a) Class $2\left(T=350^{\circ} \mathrm{C}\right)$, (b) Class 3 (Polished)
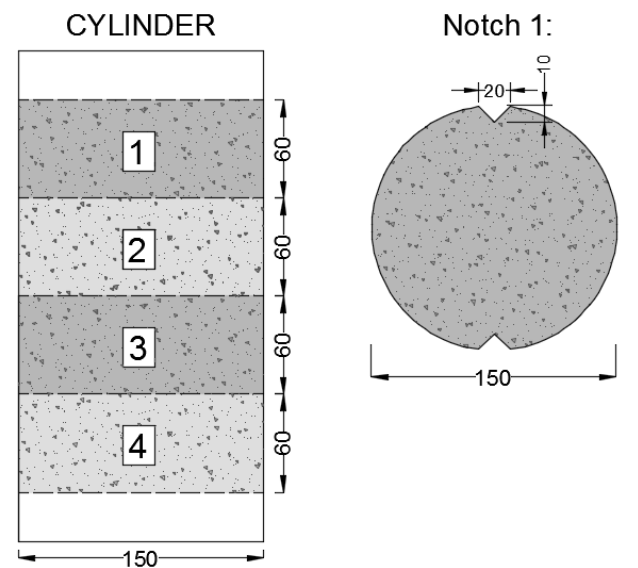

Notch 2:

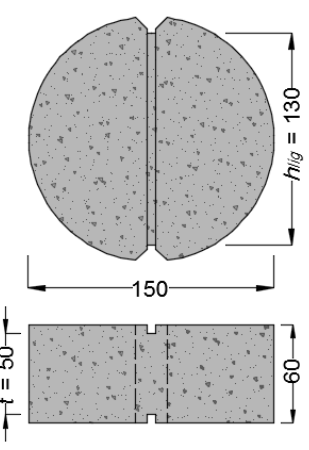

Figure 5 - Cutting of cylinders in $\phi 150 \times 300 \mathrm{~mm}$ specimens and implementation of the respective specimen's notches (units in millimeters) 


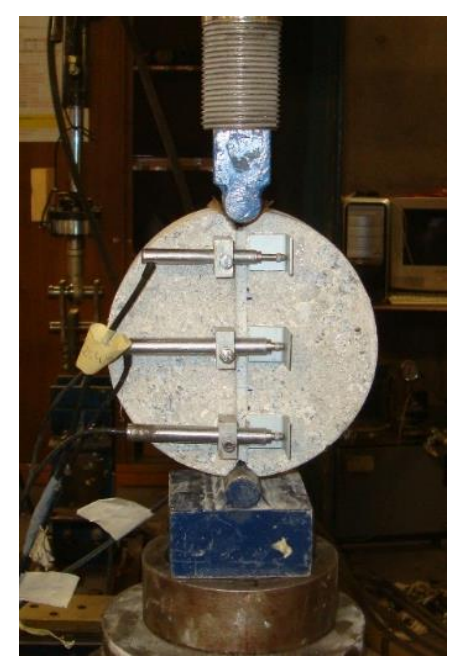

(a)

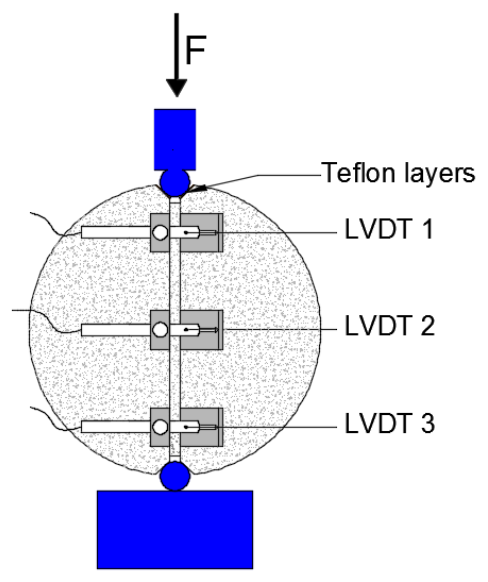

(c)

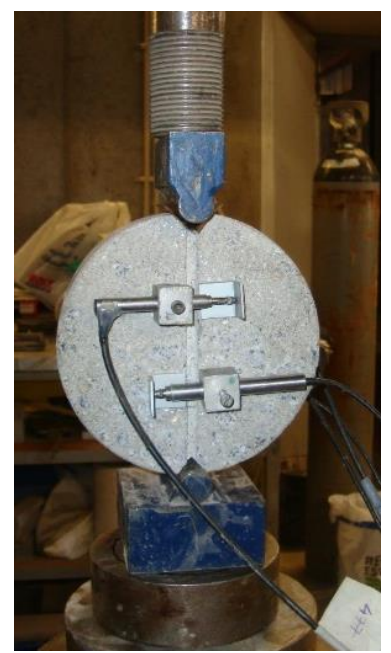

(b)

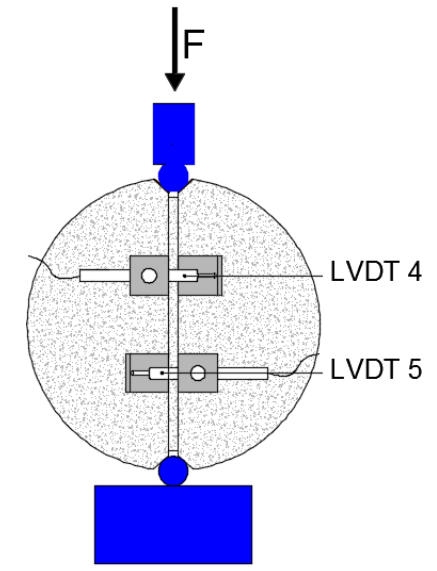

(d)

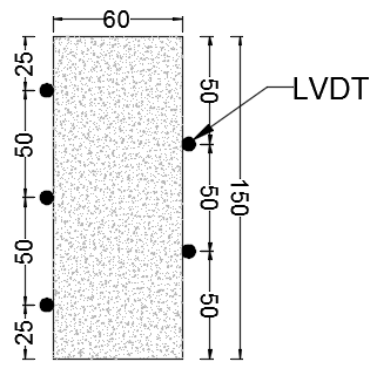

(e)

Figure 6 - Test setup for splitting tensile tests (a) (c) Specimen front view; (b) (d) Specimen back view; (e) Specimen lateral view (units in millimeters) 


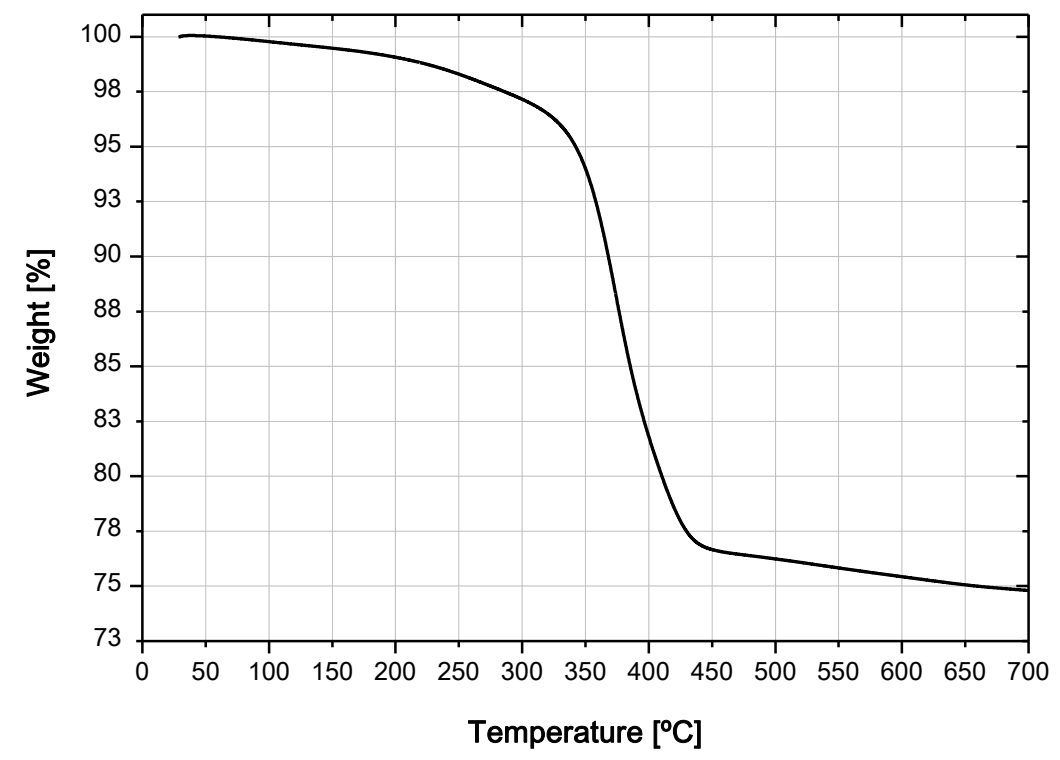

Figure 7 - TGA analysis of RSF up to $700 \stackrel{\circ}{\circ}$

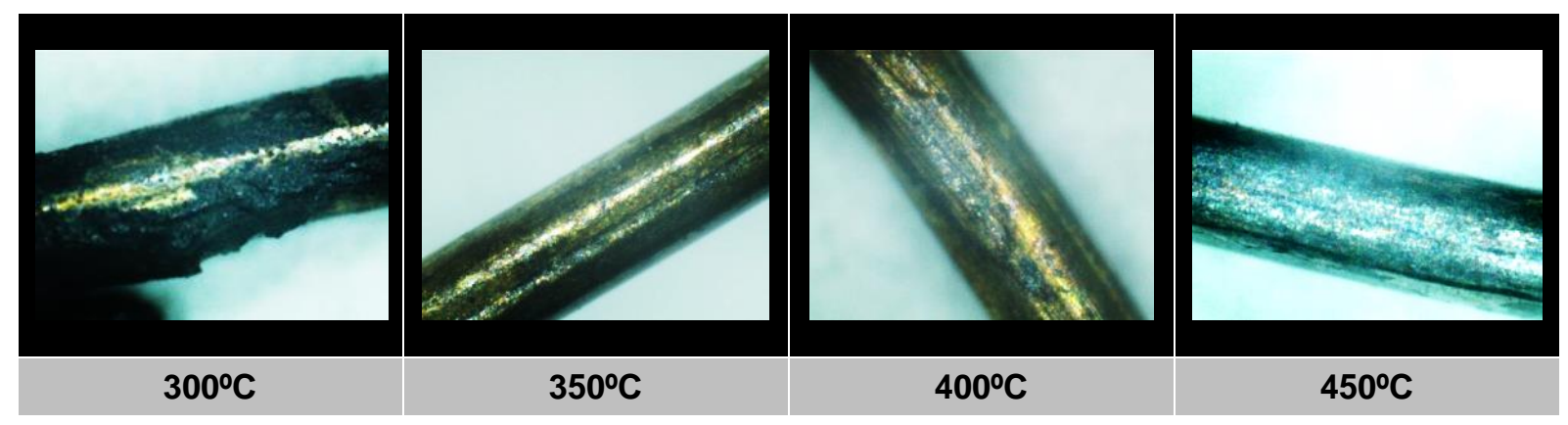

Figure 8 - Images of the RSF after firing for 1 hour at the selected temperatures

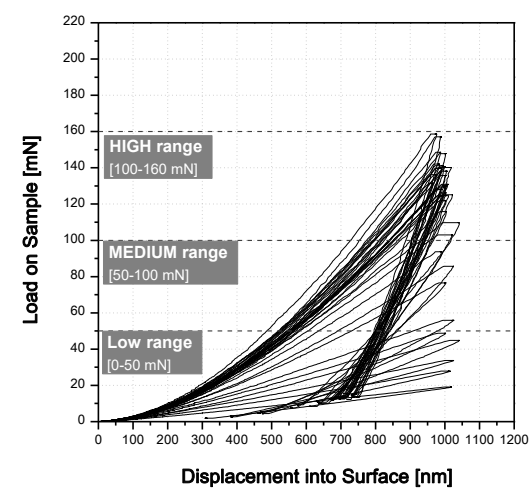

(a)

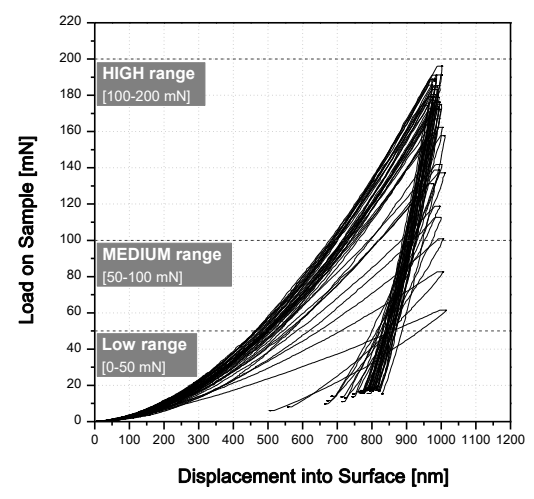

(b)

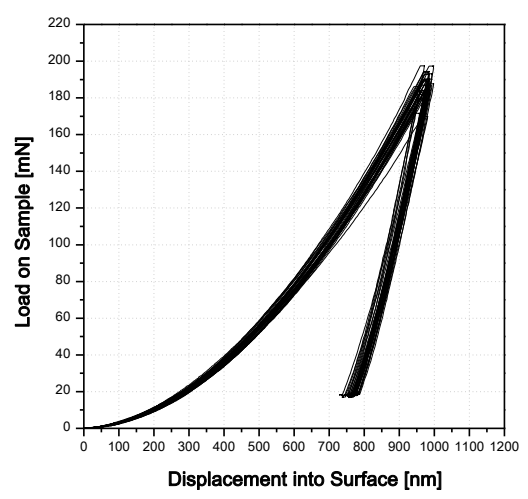

(c)

Figure 9 - Load vs. displacement curves obtained in nano-indentation tests of RSF: (a) Class 1 (reference); (b) Class $2\left(350^{\circ} \mathrm{C}\right)$; (c) Class 3 (polished) 


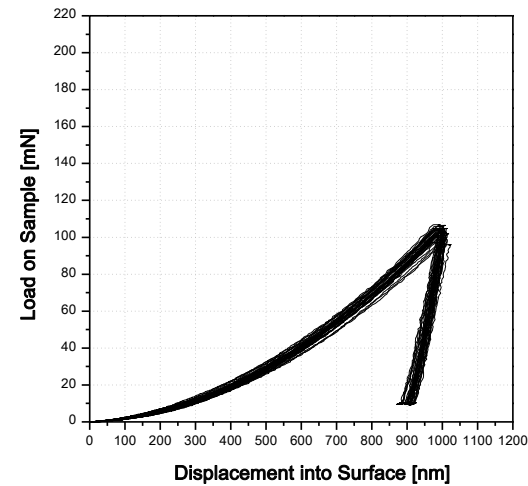

(a)

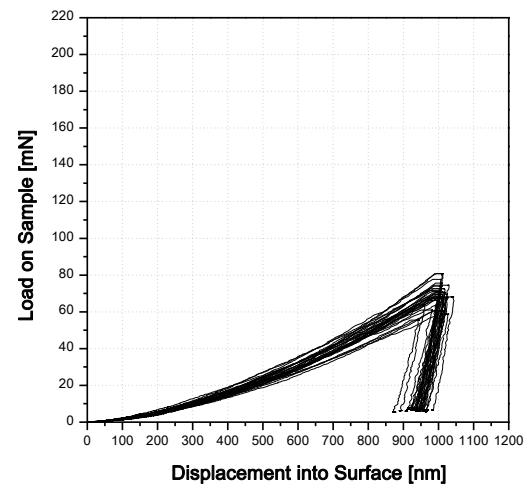

(b)

Figure 10 - Load vs. displacement curves obtained in nano-indentation tests of ISF: (a) Class 1 (reference);

(b) Class $2\left(350^{\circ} \mathrm{C}\right)$

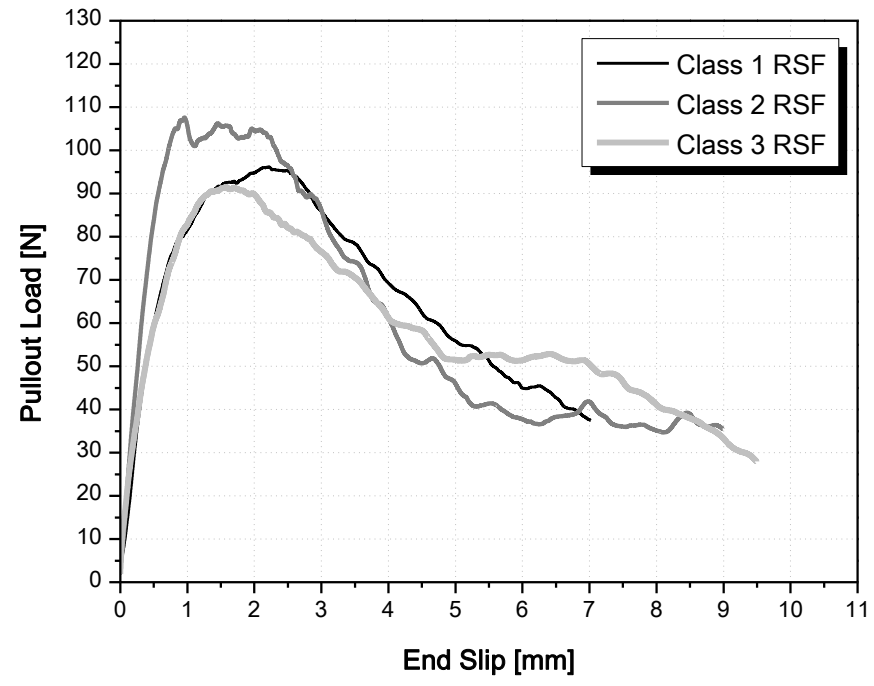

Figure 11 - Average Pullout load vs. End slip curves obtained in fiber pullout tests of RSF

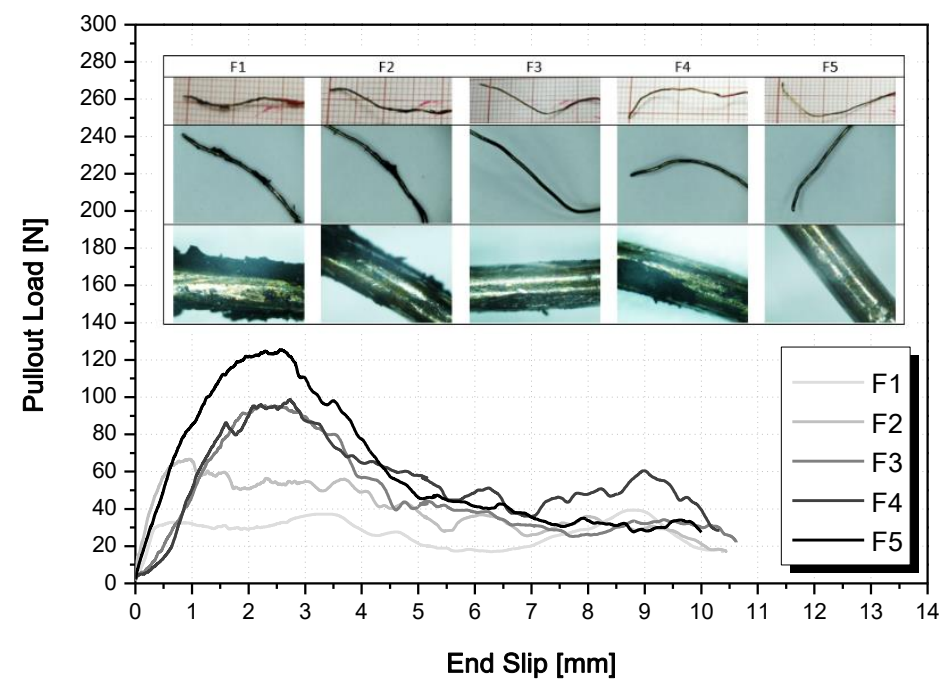

Figure 12 - Average Pullout load vs. End slip curves obtained of five different types of RSF class 1 (The level of rubber attached to the fibers decreased from F1 to F5) 


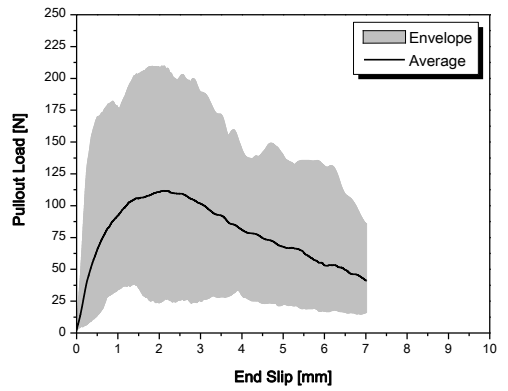

(a)

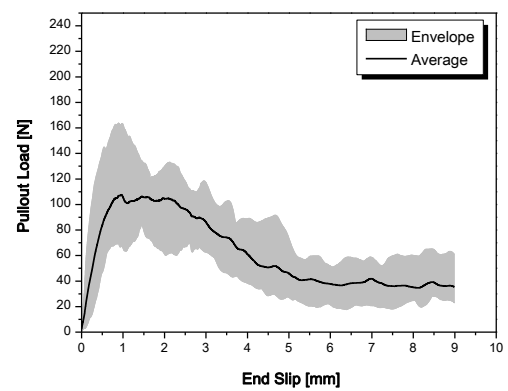

(b)

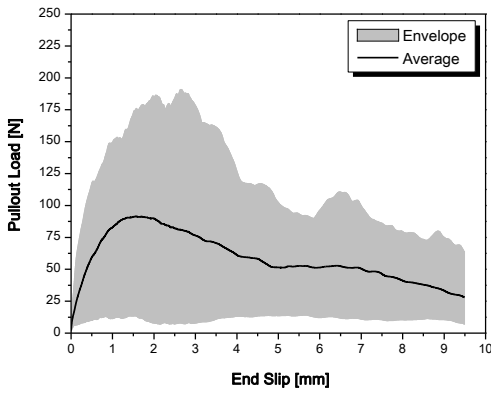

(c)

Figure 13 - Average and envelope pullout load vs. end slip curves for RSF:

(a) Class 1 (reference), (b) Class $2\left(350^{\circ} \mathrm{C}\right)$ and (c) Class 3 (polished)

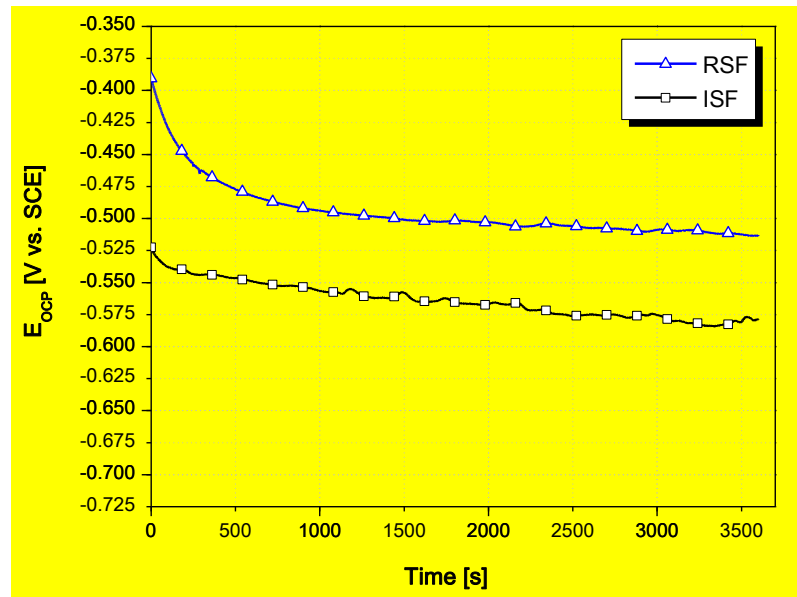

(a)

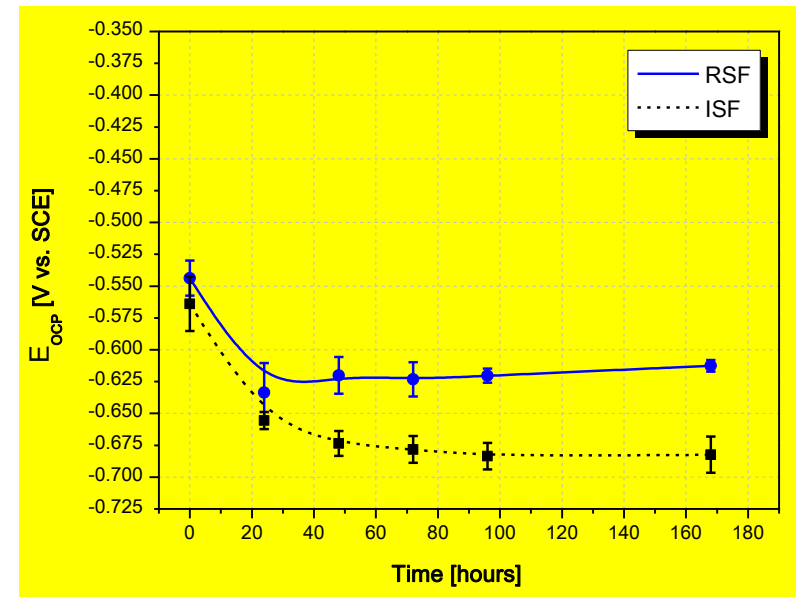

(b)

Figure 14 - Evolution of $E_{O C P}$ in RSF over the immersion period of:

(a) 1 hour (Series I), (b) 7 days (Series III). Results are compared with those reported in [21].

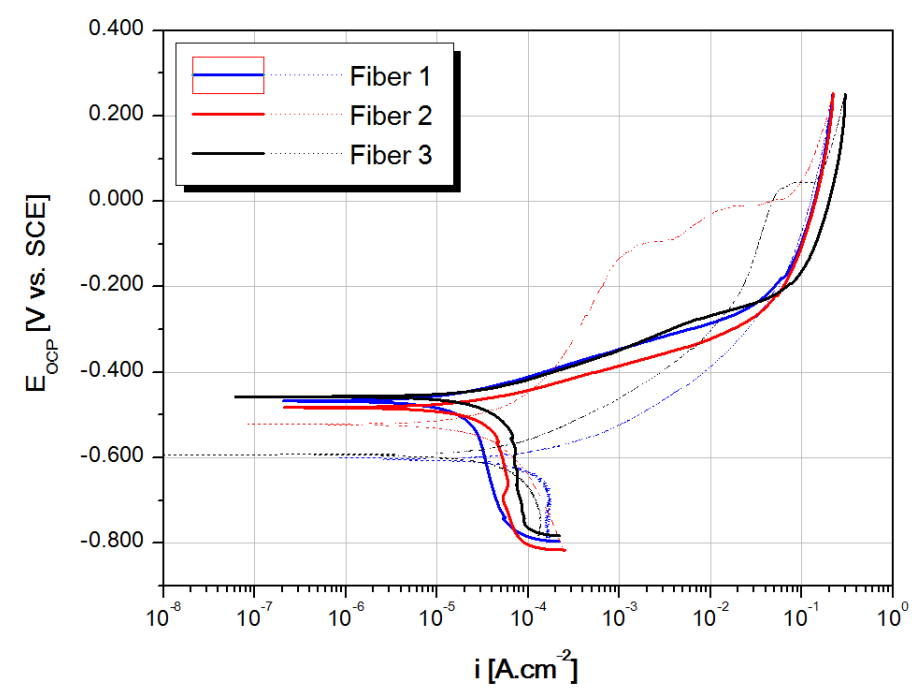

Figure 15 - Cyclic polarization curves in three RSF of class 1 - Series I (forward \& reverse scan) 


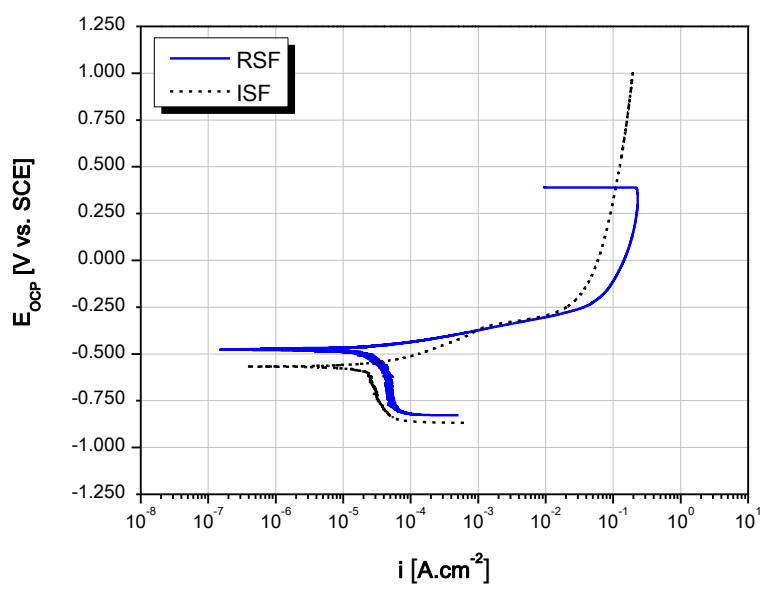

(a)

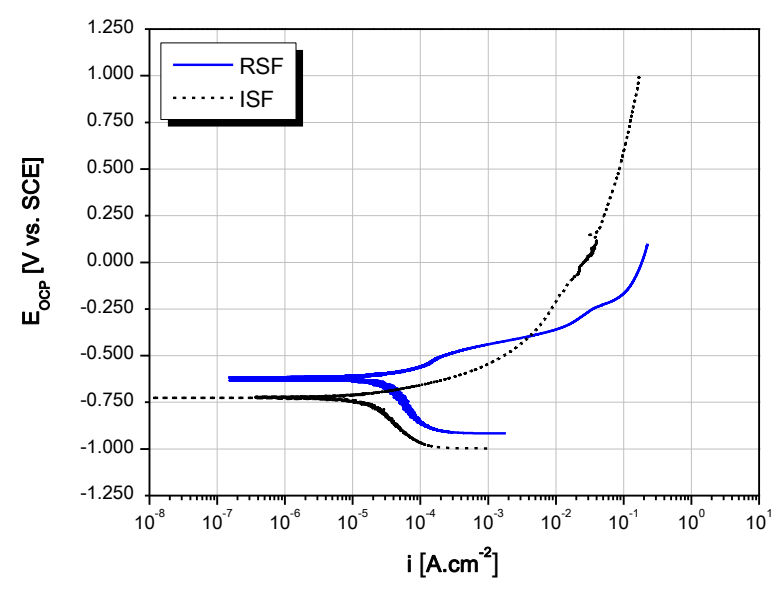

(b)

Figure 16 - Potentiodynamic polarization curves after the immersion period of:

(a) 1 hour (Series II), (b) 7 days (Series III). Results are compared with those reported in [21].

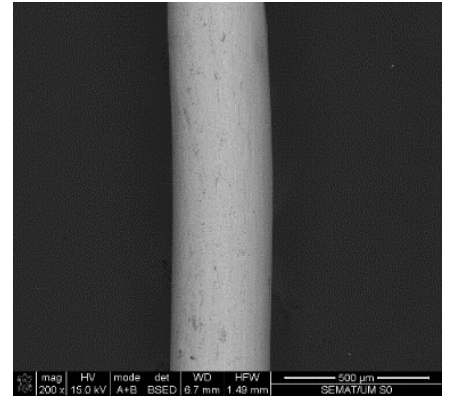

(a)

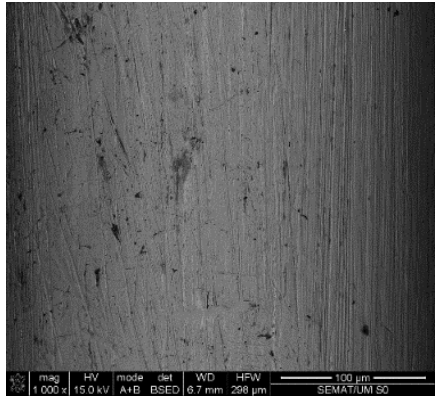

(b)

Figure 17 - SEM micrographs of the surface of polished RSF before polarization tests (without corrosion) Magnification: (a) 200x (b) 1000x 


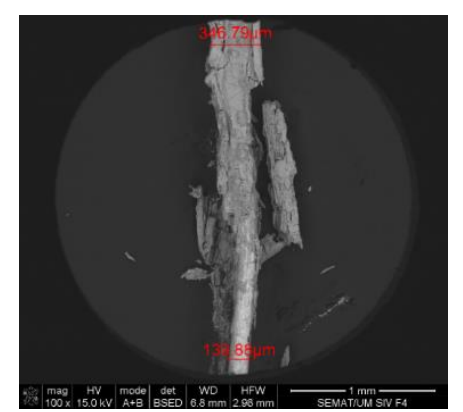

(a)

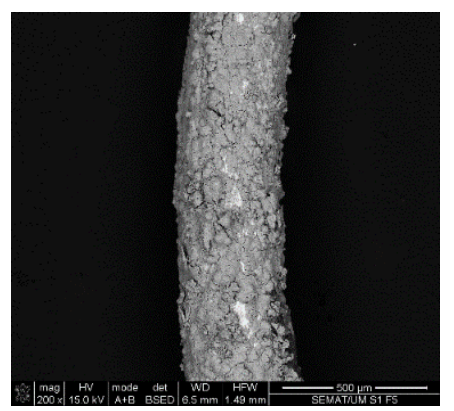

(c)

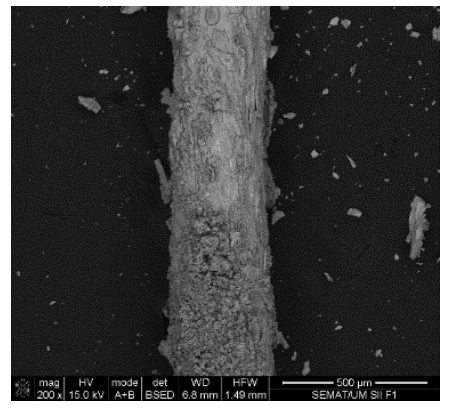

(e)

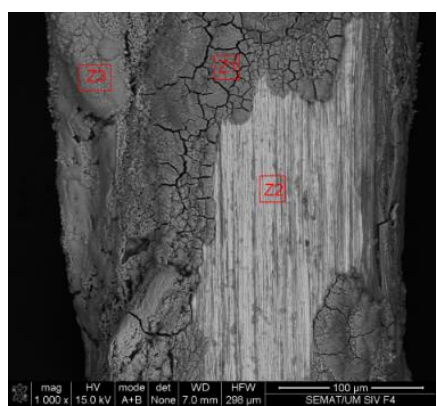

(b)

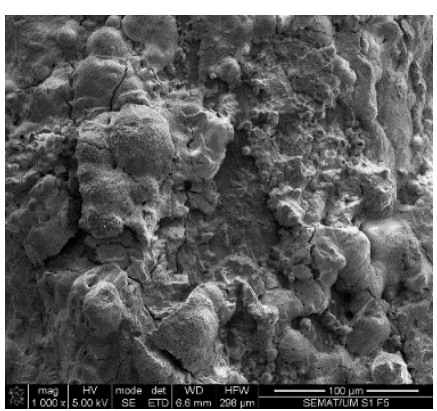

(d)

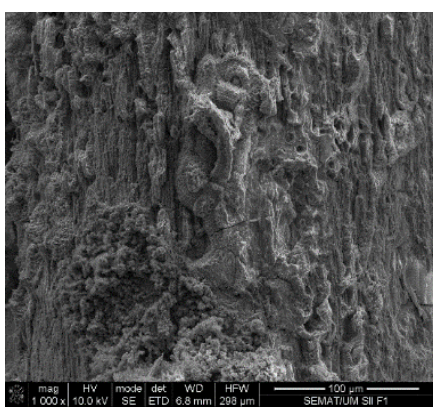

(f)

Figure 18 - SEM micrographs of the surface of polished RSF after polarization tests (with corrosion): Potentiodynamic polarization (Fiber 4 - Series II): Magnification: (a) 100x (b) 1000x (atomic contrast by backscattered electrons of chemical elements)

Linear polarization (Fiber 5 - Series IX): Magnification: (c) 200x (d) 1000x Linear polarization (Fiber 1 - Series X): Magnification: (e) 200x (f) 1000x 


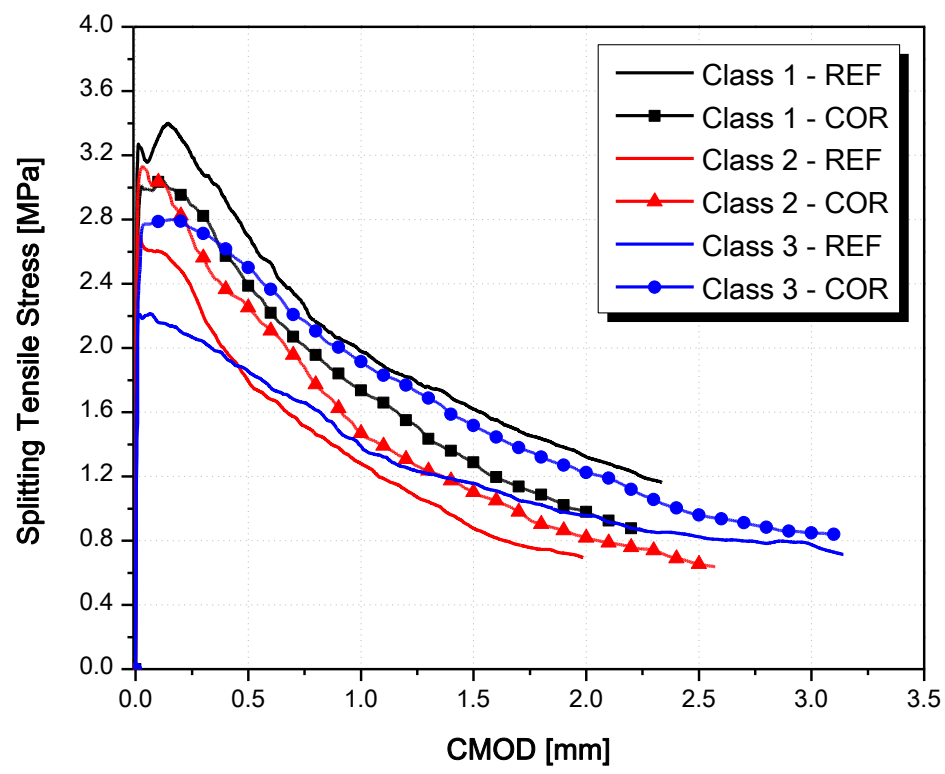

Figure 19 - Average splitting tensile stress versus crack width for specimens with RSF of class 1, 2 and 3, not exposed to $\mathrm{NaCl}$ solution (REF) or under corrosion action (COR) 